Pacific Journal of Mathematics

ON THE SINGULARITIES OF ALMOST-SIMPLE PLANE 


\title{
ON THE SINGULARITIES OF ALMOST-SIMPLE PLANE CURVES
}

\author{
TIBOR BISZTRICZKY
}

\begin{abstract}
Let $\Gamma$ be a differentiable curve in a real projective plane $P^{2}$ intersected by every line at a finite number of points. $A$ point of $\Gamma$ is ordinary if $\Gamma$ is locally convex at that point; otherwise, the point is singular. Let the singular points of $\Gamma$ consist of $n_{1}$ inflections, $n_{2}$ cusps (cusps of the first kind) and $n_{3}$ beaks (cusps of the second kind). Then $\Gamma$ is singular if $n(\Gamma)=n_{1}+n_{2}+n_{3}>0$; otherwise, $\Gamma$ is non-singular. The following questions arise naturally: Under what conditions is $\Gamma$ singular? What is then the minimum value of $n(\Gamma)$ and is it dependent or independent of the type of singularities that $\Gamma$ may possess? Presently, we determine a class of curves $\Gamma$ for which $n(\Gamma) \geq 2$ but $n_{1}+2 n_{2}+n_{3}$ $\geq 4$.
\end{abstract}

1. Introduction. Since $\Gamma$ is intersected by every line at a finite number of points, all lines of $P^{2}$ which contain no singular points and are not a tangent at any point of $\Gamma$ have the following property: either all meet $\Gamma$ at an odd number of points or all meet $\Gamma$ at an even number of points. In the case of the former [latter], we say that $\Gamma$ is of odd [even] order. Then with regard to the questions posed, curves of odd order are singular, there exists a curve of odd order containing exactly one singular point (cf. pp. 1-7, [1]), and a theorem of Möbius [2] states that a simple (without self-intersections) curve of odd order with no cusps or beaks contains at least three inflections.

Henceforth we assume that our curves are of even order. Since those conics not met by some line of $P^{2}$ are trivially non-singular, we also assume that the curves of even order consideration are met by every line in $P^{2}$. The last restriction is associated with the number $m(\Gamma)$ of multiple (self-intersection) points that $\Gamma$ may possess. In Figure 1, we present a non-singular $\Gamma$ of even order which is met by every line in $P^{2}$ and contains three double points. Thus we may certainly restrict our attention to curves $\Gamma$ for which $m(\Gamma)$ is finite. We also observe in this example that each double point decomposes the curve into two (not necessarily differentiable) closed curves, each of which is not met by some line. Thus we are faced with two possible restrictions: assume that $m(\Gamma) \leq 2$ or that no multiple point of $\Gamma$ has the mentioned property of the double points in Figure 1. In subsequent papers we will consider the case $m(\Gamma) \leq 2$. 
Presently we assume that $\Gamma$ is almost-simple; that is, each multiple point of $\Gamma$ decomposes $\Gamma$ into curves, each of which is met by every line in $P^{2}$. Under these hypotheses, our main theorem states that $n(\Gamma) \geq 2$ and $n_{1}+2 n_{2}+n_{3} \geq 4$. As examples of the minimal cases, we refer to Figure $3\left(n_{2}=2, n_{1}=n_{3}=0\right)$, Figure $4\left(n_{1}=n_{2}=n_{3}=1\right)$ and Figure $5\left(n_{1}=\right.$ $\left.n_{3}=2, n_{2}=0\right)$.

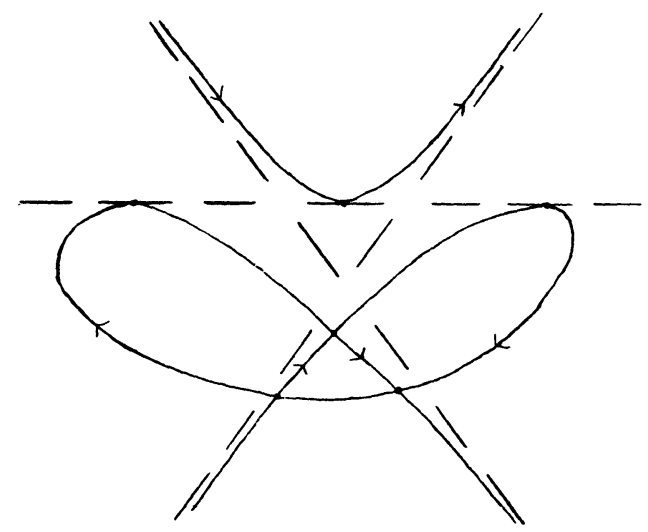

Figure 1

2. Differentiable curves. In this section we introduce our notation, present formal definitions and list results required for the proof of the main theorem. As these results are known or readily evident, they are presented without proofs. For a rigorous and complete treatment, we refer the reader to [3].

We assume that $P^{2}$ has the usual topology. Let $p, q, \ldots$ and $L, M, \ldots$ denoted the points and lines of $P^{2}$ respectively. The flat of $P^{2}$ spanned by $p, L, \ldots$ is denoted by $\langle p, L, \ldots\rangle$.

Let $T \subset P^{2}$ be an oriented line. For $t_{0} \neq t_{1}$ in $T$, let $\left[t_{0}, t_{1}\right]$ denote the oriented closed segment of $T$ with initial point $t_{0}$ and terminal point $t_{1}$. We put $\left(t_{0}, t_{1}\right)=\left[t_{0}, t_{1}\right] \backslash\left\{t_{0}, t_{1}\right\},\left[t_{0}, t_{1}\right)=\left[t_{0}, t_{1}\right] \backslash\left\{t_{1}\right\}$ and $\left(t_{0}, t_{1}\right] \backslash\left\{t_{0}\right\}$. Hence $T=\left[t_{0}, t_{1}\right] \cup\left(t_{1}, t_{0}\right)=\left[t_{0}, t_{1}\right) \cup\left[t_{1}, t_{0}\right)$. If $U(t)=\left(t_{0}, t_{1}\right)$ is a neighbourhood of $t$ in $T$ then $U^{-}(t)=\left(t_{0}, t\right), U^{+}(t)=\left(t, t_{1}\right)$ and $U^{\prime}(t)$ $=U^{-}(t) \cup U^{+}(t)$.

A curve $\Gamma$ is a continuous map from $T$ into $P^{2} . \Gamma$ is (directly) differentiable if the tangent line $\Gamma_{1}(t)=\lim \left\langle\Gamma(t), \Gamma\left(t^{\prime}\right)\right\rangle$, as $t^{\prime} \neq t$ tends to $t$ in $T$, exists for each $t \in T$ and any line of $P^{2}$ meets $\Gamma$ at a finite number of points. Henceforth $\Gamma$ is differentiable and we identify $\Gamma(T)$ with $\Gamma$.

Let $\Re \subseteq T$ be a segment. We call $\Gamma / \mathcal{T}$ a subarc of $\Gamma$ and identify $\Gamma / \Re$ with $\Gamma(\Re)$. If $n=\sup _{L \subset P^{2}}|L \cap \Gamma(\Re)|$ is finite, we say that $\Re$, or equivalently $\Gamma(\Re)$, is of order $n$. The order of a point $t \in T, \operatorname{ord}(t)$, is 
the minimum order which an $U(t)$ can possess. Clearly ord $(t) \geq 2$. Then $t$ is ordinary if $\operatorname{ord}(t)=2$; otherwise, $t$ is singular. We say that $t$ is elementary if there exist $U^{-}(t)$ and $U^{+}(t)$ of order two. A subarc of $\Gamma$ is ordinary [elementary] if each of its points is ordinary [elementary].

Let $t \in T$ and $L \subset P^{2}$. We say that $L$ supports $\Gamma$ at $t$ if there is an $L^{\prime} \neq L$ with $\Gamma(t) \notin L^{\prime}$ and an $U^{\prime}(t)$ such that $\Gamma\left(U^{\prime}(t)\right)$ is contained in one of the open half-planes of $P^{2}$ determined by $L$ and $L^{\prime}$. When $L$ does not support $\Gamma$ at $t$, we say that $L$ cuts $\Gamma$ at $t$. Let $S(t)=\left\{L \subset P^{2} \mid \Gamma(t) \in\right.$ $\left.L \neq \Gamma_{1}(t)\right\}$. It is known that either all $L \in S(t)$ cut $\Gamma$ at $t$ or all $L \in S(t)$ support $\Gamma$ at $t$. Thus there are four types of points in $T$ with respect to $\Gamma: t$ is regular if $L \in S(t)\left[\Gamma_{1}(t)\right]$ cuts [supports] $\Gamma$ at $t ; t$ is an inflection if $L \in S(t)$ and $\Gamma_{1}(t)$ both cut $\Gamma$ at $t$; $t$ is a beak if $L \in S(t)$ and $\Gamma_{1}(t)$ both support $\Gamma$ at $t ; t$ is a cusp if $L \in S(t)\left[\Gamma_{1}(t)\right]$ supports [cuts] $\Gamma$ at $t$. In Figure $4, t_{1}$ is a cusp, $t_{2}$ is a beak, $t_{3}$ is an inflection and all other points are regular. Trivially, an ordinary point is regular and hence inflections, cusps and beaks are singular.

Next, $\Gamma$ is of odd [even] order if every line in $P^{2}$ cuts $\Gamma$ at an odd [even] number of points. Since every line meets $\Gamma$ at a finite number of points, $\Gamma$ is clearly of odd or even order. Let $\Re \subseteq T$. The index of $\Gamma(\mathscr{N})$, $\operatorname{ind}(\Gamma(\Re))$, is the minimum number of points of $\Gamma(\mathscr{N})$ which can lie on any line of $P^{2}$. Thus if $\Gamma$ is of odd order, $\operatorname{ind}(\Gamma)>0$. Let $t \in \mathfrak{T}$. Then $\Gamma(t)$ is a simple point of $\Gamma(\Re)$ if $\Gamma\left(t^{\prime}\right) \neq \Gamma(t)$ for $t^{\prime} \in \Re \backslash\{t\}$; otherwise, $\Gamma(t)$ is a multiple point of $\Gamma(\Re)$. We similarly define a multiple tangent of $\Gamma(\mathscr{N})$. We say that $\Gamma(\mathscr{T})$ is simple if each of its points is simple. Finally $\Gamma$ is almost-simple if $\Gamma(t)=\Gamma\left(t^{\prime}\right)$ for $t \neq t^{\prime}$ implies that ind $\left(\Gamma\left[t, t^{\prime}\right]\right)$ and $\operatorname{ind}\left(\Gamma\left[t^{\prime}, t\right]\right)$ are both positive.

As stated in the introduction, we are interested in almost-simple curves $\Gamma$ with the property that $\Gamma$ is of even order, $n(\Gamma)<\infty$ and $m(\Gamma)<\infty$. The conditions that $n(\Gamma)$ and $m(\Gamma)$ are finite however imply that $\Gamma$ is elementary, that is, not only is $\Gamma$ locally convex at all except a finite number of points but each point of $\Gamma$ also has one-sided neighbourhoods of order two. Such curves have been extensively studied and we list some of their important properties.

1. A regular point is ordinary and hence the singular points of $\Gamma$ consist of $n_{1}$ inflections, $n_{2}$ cusps and $n_{3}$ beaks.

2. $n_{1}+2 n_{2}+n_{3}$ is even if and only if $\Gamma$ is of even order.

3. The tangents $\Gamma_{1}(t)$ of $\Gamma$ depend continuously on $t \in T$.

4. Let $\Gamma(t)$ be simple and let $L=\lim \left\langle\Gamma\left(t^{\prime}\right), \Gamma\left(t^{\prime \prime}\right)\right\rangle$ as $t^{\prime} \neq t^{\prime \prime}$ tend to $t$. If $t$ is an ordinary or an inflection point then $L=\Gamma_{1}(t)$.

5. Let $t \in T$ and $p \in P^{2}$. Then there is an $U^{\prime}(t)$ such that $p \notin \Gamma_{1}\left(t^{\prime}\right)$ for $t^{\prime} \in U^{\prime}(t)$. 
6. Let $\Gamma\left(t_{1}, t_{2}\right)$ be a regular (ordinary) simple subarc such that there is a line through $\Gamma\left(t_{1}\right)$ and $\Gamma\left(t_{2}\right)$ not meeting $\Gamma\left(t_{1}, t_{2}\right), \Gamma\left(t_{1}\right) \neq \Gamma\left(t_{2}\right)$. If $\Gamma\left(t_{1}\right) \notin \Gamma_{1}(t)$ for $t \in\left(t_{1}, t_{2}\right)$ or $\Gamma\left(t_{2}\right) \notin \Gamma_{1}(t)$ for $t \in\left(t_{1}, t_{2}\right)$, then $\left(t_{1}, t_{2}\right)$ is of order two.

Finally we note that our definitions and results were presented in terms of continuity and the manner in which lines of $P^{2}$ meet the curve. As the basic subarc of these curves is a subarc of order two, we also list some of the properties of such a subarc.

Let $\left(t_{0}, t_{1}\right)$ be of order two and let $N$ be an oriented line such that $N \cap \Gamma\left(t_{0}, t_{1}\right)=\varnothing$. For $t \in\left(t_{0}, t_{1}\right), \Gamma_{1}(t)$ meets $N$ at exactly one point which we denote by $\varphi(t)$.

7. $\left|\Gamma_{1}(t) \cap \Gamma\left[t_{0}, t_{1}\right]\right|=1$ for $t \in\left(t_{0}, t_{1}\right), \lim \left(\Gamma_{1}(t) \cap \Gamma_{1}\left(t_{i}\right)\right)=\left\{\Gamma\left(t_{i}\right)\right\}$ as $t$ tends to $t_{l}$ and $\lim \left(\left\langle\Gamma\left(t^{\prime}\right), \Gamma\left(t^{\prime \prime}\right)\right\rangle \cap \Gamma_{1}\left(t_{l}\right)\right)=\left\{\Gamma\left(t_{l}\right)\right\}$ as $t^{\prime} \neq t^{\prime \prime}$ tend to $t_{i}$ in $\left(t_{0}, t_{1}\right), i=0,1$.

8. If $\varphi$ is not onto then $\varphi$ is a strictly monotone map.

\section{The main theorem.}

1. THEOREM. Let $\Gamma$ be almost-simple, elementary with positive index and of even order. Then

(i) $n(\Gamma) \geq 2$

and

(ii) $n_{1}+2 n_{2}+n_{3} \geq 4$.

Henceforth let $\Gamma: T \rightarrow P^{2}$ satisfy the hypothesis of 3.1. Let $t \in T$. Then there is an $U(t)=\left(t_{0}, t_{1}\right)$ such that both $\left(t_{0}, t\right)$ and $\left(t, t_{1}\right)$ are of order two. Let $N$ be an oriented line such that $N \cap \Gamma\left(t_{0}, t_{1}\right)=\varnothing, N$ meets $\Gamma_{1}\left(t^{\prime}\right)$ at the point $\varphi\left(t^{\prime}\right)$ for $t^{\prime} \in \Gamma\left(t_{0}, t_{1}\right)$ and $\varphi$ is not onto. If $t$ is regular (equivalently ordinary), then we may assume that $\left(t_{0}, t_{1}\right)$ is of order two and thus $\varphi$ is strictly monotone by 1.8. In any case, $\varphi /\left(t_{0}, t\right]$ and $\varphi /\left[t, t_{1}\right)$ are both strictly monotone. As $\varphi$ is not onto, $\varphi\left(\left(t_{0}, t\right)\right) \cap$ $\varphi\left(\left(t, t_{1}\right)\right) \neq \varnothing$ implies that either $\varphi\left(\left(t_{0}, t\right)\right) \subseteq \varphi\left(\left(t, t_{1}\right)\right)$ or $\varphi\left(\left(t, t_{1}\right)\right) \subseteq$ $\varphi\left(\left(t_{0}, t\right)\right)$. It is easy to check that.

2. LEMMA $\varphi\left(\left(t_{0}, t_{1}\right)\right) \cap \varphi\left(\left(t, t_{1}\right)\right)=\varnothing$ if and only if $t$ is a regular or $a$ cusp point.

We wish to relate this monotone intersection property of the tangents of $U(t)$ with $N$ to the subarcs of $\Gamma$ met by these tangents. To this end, we introduce the following definitions. 
Let $\mathbb{N}$ and $\Re^{\prime}$ be segments of $T$ such that $\Gamma(\Re) \cap \Gamma\left(\mathscr{N}^{\prime}\right)=\varnothing$ and $\Gamma_{1}(\mathrm{t}) \cap \Gamma\left(\Re^{\prime}\right) \neq \varnothing$ for each $\mathrm{t} \in \mathfrak{T}^{\prime}$. If $\left|\Gamma_{1}(t) \cap \Gamma\left(\mathscr{N}^{\prime}\right)\right|=1$ for each $t \in \mathfrak{K}$, we write $\mathfrak{K} \rightarrow \mathfrak{K}^{\prime}$. (Since $\Gamma$ is elementary, $\mathfrak{N} \rightarrow \mathfrak{K}^{\prime}$ and 1.3 readily imply that $\Gamma_{1}(t)$ cuts $\Re^{\prime}$ at the point of intersection.) If for each $t^{\prime} \in \mathscr{N}^{\prime}$ there is exactly one $t \in \mathscr{T}$ such that $\Gamma\left(t^{\prime}\right) \in \Gamma_{1}(t)$ and moreover $\Gamma_{1}(t)$ cuts $\Re^{\prime}$ at $t^{\prime}$, we write $\Re \leftarrow \Re^{\prime}$. If both $\Re \rightarrow \Re^{\prime}$ and $\Re \leftarrow \Re^{\prime}$, then clearly $\Gamma_{1}(t), t \in \Re$, meets $\Gamma\left(\Re^{\prime}\right)$ in a strictly monotone manner and we write $\mathfrak{N} \leftrightarrow \mathfrak{K}^{\prime}$.

3. Lemma. Let $\Gamma_{1}\left(s_{0}\right)$ cut $\Gamma$ at $\Gamma\left(t_{0}\right) \neq \Gamma\left(s_{0}\right)$. Then there exist $U\left(s_{0}\right)$ and $U\left(t_{0}\right)$ such that $U\left(s_{0}\right) \rightarrow U\left(t_{0}\right)$ and $\Gamma\left(t_{0}\right) \notin \Gamma_{1}(s)$ for any $s \in U^{\prime}\left(s_{0}\right)$.

Proof. Clearly there exist open neighbourhoods $V\left(s_{0}\right)$ and $V\left(t_{0}\right)$ in $T$ such that $\Gamma\left(V\left(s_{0}\right)\right) \cap \Gamma\left(V\left(t_{0}\right)\right)=\varnothing, \Gamma_{1}\left(s_{0}\right) \cap \Gamma\left(V\left(t_{0}\right)\right)=\left\{\Gamma\left(t_{0}\right)\right\}$ and by 1.5, $\Gamma\left(t_{0}\right) \notin \Gamma_{1}(s)$ for $s \in V^{-}\left(s_{0}\right)$. As $\Gamma$ is elementary, we may assume that $V^{-}\left(s_{0}\right), V^{+}\left(s_{0}\right), V^{-}\left(t_{0}\right)$ and $V^{+}\left(t_{0}\right)$ are all of order two. Finally as $\Gamma_{1}\left(s_{0}\right)$ cuts $\Gamma$ at $t_{0}$, we may assume that $\Gamma_{1}(s) \cap \Gamma\left(V\left(t_{0}\right)\right) \neq \varnothing$ for $s \in V\left(s_{0}\right)$.

Suppose there exist $s_{\lambda}$ tending to $s_{0}$ in say $V^{-}\left(s_{0}\right)$ such that $\Gamma_{1}\left(s_{\lambda}\right)$ meets $V\left(t_{0}\right)$ at $t_{\lambda} \neq t_{\lambda}^{\prime}$ for each $s_{\lambda}$. By 1.3 , both $t_{\lambda}$ and $t_{\lambda}^{\prime}$ tend to $t_{0}$ as $s_{\lambda}$ tends to $s_{0}$. Since $\Gamma_{1}\left(s_{0}\right)$ cuts $\Gamma$ at $t_{0}, t_{0}$ is not a beak. If $t_{0}$ is a cusp, then $\Gamma_{1}\left(s_{0}\right)=\Gamma_{1}\left(t_{0}\right)$. If $t_{0}$ is not a cusp, then 1.4 implies that

$$
\Gamma_{1}\left(s_{0}\right)=\lim \Gamma_{1}\left(s_{\lambda}\right)=\lim \left\langle\Gamma\left(t_{\lambda}\right), \Gamma\left(t_{\lambda}^{\prime}\right)\right\rangle=\Gamma_{1}(t)
$$

as $s_{\lambda}$ tends to $s_{0}$ and thus $t_{0}$ is an inflection point. In any case, $\Gamma_{1}\left(s_{0}\right)=$ $\Gamma_{1}\left(t_{0}\right)$ and $\operatorname{ord}\left(t_{0}\right)=3$. From this, it readily follows that for $\Gamma_{1}\left(s_{\lambda}\right)=$ $\left\langle\Gamma\left(t_{\lambda}\right), \Gamma\left(t_{\lambda}^{\prime}\right)\right\rangle$ close to $\Gamma_{1}\left(t_{0}\right)$, either $\Gamma_{1}\left(s_{\lambda}\right)$ supports and cuts $\Gamma$ in $V^{\prime}\left(t_{0}\right)$ or $\Gamma_{1}\left(s_{\lambda}\right)$ cuts $\Gamma$ at three points of $V\left(t_{0}\right)$. Since $V^{-}\left(t_{0}\right)$ and $V^{+}\left(t_{0}\right)$ are of order two and $\Gamma\left(t_{0}\right) \notin \Gamma_{1}\left(s_{\lambda}\right)$, such $\Gamma_{1}\left(s_{\lambda}\right)$ is either a tangent of $\Gamma\left(V^{-}\left(t_{0}\right)\right)$ or cuts $\Gamma$ at two points of $V^{-}\left(t_{0}\right)$ say. In either case, 1.7 implies that

$$
\begin{aligned}
\left\{\Gamma\left(s_{0}\right)\right\} & =\lim _{s_{\lambda} \rightarrow s_{0}}\left(\Gamma_{1}\left(s_{\lambda}\right) \cap \Gamma_{1}\left(s_{0}\right)\right) \\
& =\lim _{s_{\lambda} \rightarrow s_{0}}\left(\Gamma_{1}\left(s_{\lambda}\right) \cap \Gamma_{1}\left(t_{0}\right)\right)=\left\{\Gamma\left(t_{0}\right)\right\},
\end{aligned}
$$

a contradiction. Hence $\left|\Gamma_{1}\left(s_{\lambda}\right) \cap \Gamma\left(V\left(t_{0}\right)\right)\right|=1$ for $s_{\lambda}$ sufficiently close to $s_{0}$ in $V\left(s_{0}\right)$.

4. Lemma. Let $\Gamma_{1}\left(s_{0}\right)$ cut $\Gamma$ at $\Gamma\left(t_{0}\right) \neq \Gamma\left(s_{0}\right)$. Then there exist $U\left(s_{0}\right)$ and $U\left(t_{0}\right)$ such that either $U^{+}\left(s_{0}\right) \leftrightarrow U^{-}\left(t_{0}\right)$ or $U^{+}\left(s_{0}\right) \leftrightarrow U^{+}\left(t_{0}\right)$ and either $U^{-}\left(s_{0}\right) \leftrightarrow U^{-}\left(t_{0}\right)$ or $U^{-}\left(s_{0}\right) \leftrightarrow U^{+}\left(t_{0}\right)$. 
Proof. By 3.3, there exist $V\left(s_{0}\right)$ and $V\left(t_{0}\right)$ such that $V^{+}\left(s_{0}\right)$ and $V^{-}\left(s_{0}\right)$ are both of order two, $V\left(s_{0}\right) \rightarrow V\left(t_{0}\right)$ and $\Gamma\left(t_{0}\right) \notin \Gamma_{1}(s)$ for $s \in V^{\prime}\left(s_{0}\right)$. By 1.3, $\Gamma_{1}(s) \cap \Gamma\left(V^{+}\left(t_{0}\right)\right)=\varnothing$ for $s \in V^{+}\left(s_{0}\right)$ say and hence $V^{+}\left(s_{0}\right) \rightarrow V^{-}\left(t_{0}\right)$. Set $V^{-}\left(t_{0}\right)=\left(t_{1}, t_{0}\right)$ and let $U^{+}\left(s_{0}\right) \subseteq V^{+}\left(s_{0}\right)$ such that some $\bar{t} \in\left(t_{1}, t_{0}\right)$ does not lie on any tangent of $U^{+}\left(s_{0}\right)$.

Suppose there is a $t^{*} \in\left(t_{1}, t_{0}\right)$ such that $\Gamma\left(t^{*}\right)=\Gamma_{1}\left(s_{1}\right) \cap \Gamma_{1}\left(s_{2}\right)$, $s_{1}<s_{2}$ in $U^{+}\left(s_{0}\right)$. Let $\mathscr{P}_{1}$ and $\mathscr{P}_{2}$ be the closed half-planes determined by $\Gamma_{1}\left(s_{1}\right)$ and $\Gamma_{1}\left(s_{2}\right)$. Since $U^{+}\left(s_{0}\right)$ is of order two, $\Gamma\left(U^{+}\left(s_{0}\right)\right) \subset \mathscr{P}_{1}$ say by 1.7. Let $\mathscr{P}_{11}$ and $\mathscr{P}_{12}$ be the open disjoint regions of $\operatorname{int}\left(\mathscr{P}_{1}\right)$ determined by $\Gamma\left(s_{1}, s_{2}\right), \Gamma\left(s_{0}, s_{1}\right) \subset \mathscr{P}_{11}$ say. Then each point of $\mathscr{P}_{2} \cup \mathscr{P}_{12}$ lies on at least one tangent of $U^{+}\left(s_{0}\right)$. Hence $\Gamma_{1}(s) \cap \Gamma\left(V^{+}\left(t_{0}\right) \cup\left\{t_{0}\right\}\right)=\varnothing$ for $s \in$ $U^{+}\left(s_{0}\right)$ implies that $\Gamma\left(V^{+}\left(t_{0}\right) \cup\left\{t_{0}\right\}\right) \subset \mathscr{P}_{11}$. As $U^{+}\left(s_{0}\right) \rightarrow V^{-}\left(t_{0}\right), \Gamma\left(t^{*}\right)$ $=\Gamma_{1}\left(s_{1}\right) \cap \Gamma_{1}\left(s_{2}\right)$ and $\Gamma\left(t_{0}\right) \in \mathscr{P}_{11}$ yield that $\Gamma\left(t^{*}, t_{0}\right) \subset \mathscr{P}_{11}$. Clearly each point of $\left(t^{*}, t_{0}\right)$ lies on a tangent of $U^{+}\left(s_{0}\right)$ by 1.3 and thus $\bar{t} \in\left(t_{1}, t^{*}\right)$. But as both $\Gamma_{1}\left(s_{1}\right)$ and $\Gamma_{1}\left(s_{2}\right)$ cut $\Gamma$ at $t^{*}, \Gamma\left(t^{*}, t_{0}\right) \subset \mathscr{P}_{11}$ and $\Gamma\left(U^{+}\left(s_{0}\right)\right) \cap$ $\Gamma\left(V^{-}\left(t_{0}\right)\right)=\varnothing$ imply that $\Gamma\left(t_{1}, \bar{t}\right] \subset \Gamma\left(t_{1}, t^{*}\right) \subset \mathscr{P}_{12}$, a contradiction.

Since each point of $V^{-}\left(t_{0}\right)$ lies on at most one tangent of $U^{+}\left(s_{0}\right)$, it is clear that there is an $U^{-}\left(t_{0}\right) \subset V^{-}\left(t_{0}\right)$ such that $U^{+}\left(s_{0}\right) \leftarrow U^{-}\left(t_{0}\right)$ and thus $U^{+}\left(s_{0}\right) \leftrightarrow U^{-}\left(t_{0}\right)$.

The preceding is symmetric in $U^{+}\left(s_{0}\right)$ and $U^{-}\left(s_{0}\right)$.

COROLlaRY. Under the hypothesis of 3.4 , there exist $U\left(s_{0}\right)$ and $U\left(t_{0}\right)$ such that $U\left(s_{0}\right) \leftrightarrow U\left(t_{0}\right)$ if and only if $s_{0}$ is a regular or a cusp point.

Proof. Let $U\left(s_{0}\right) \rightarrow U\left(t_{0}\right)$. Then clearly $U\left(s_{0}\right) \leftrightarrow U\left(t_{0}\right)$ if and only if either $U^{+}\left(s_{0}\right) \leftrightarrow U^{+}\left(t_{0}\right)$ and $U^{-}\left(s_{0}\right) \leftrightarrow U^{-}\left(t_{0}\right)$ or $U^{+}\left(s_{0}\right) \leftrightarrow U^{-}\left(t_{0}\right)$ and $U^{-}\left(s_{0}\right) \leftrightarrow U^{+}\left(t_{0}\right)$. We now apply 3.2.

Let $\Gamma_{1}(s)$ meet $\Gamma$ at $\Gamma(t) \neq \Gamma(s)$. We say that $t$ is s-negative [s-positive $]$ if there exist $U^{+}(s)$ of order two and $U^{-}(t)\left[U^{+}(t)\right]$ such that $U^{+}(s) \leftrightarrow U^{-}(t)\left[U^{+}(s) \leftrightarrow U^{+}(t)\right]$.

By 3.4, if $\Gamma_{1}(s)$ cuts $\Gamma$ at $\Gamma(t) \neq \Gamma(s)$ then $t$ is either $s$-positive or $s$-negative. We note that $t$ may be both $s$-positive and $s$-negative or neither $s$-positive nor $s$-negative. In either case, $\Gamma_{1}(s)$ supports $\Gamma$ at $t$ if $\Gamma(s) \neq \Gamma(t)$.

Finally we observe that the following two lemmas are a direct consequence of 3.4 and the definitions.

5. Lemma. Let $t_{0}$ be $s_{0}$-negative [ $s_{0}$-positive]. Then there exist $U^{+}\left(s_{0}\right)$ and $U^{-}\left(t_{0}\right)\left[U^{+}\left(t_{0}\right)\right]$ such that $U^{+}\left(s_{0}\right) \leftrightarrow U^{-}\left(u_{0}\right)\left[U^{+}\left(s_{0}\right) \leftrightarrow U^{+}\left(t_{0}\right)\right]$ and each $t \in U^{-}\left(t_{0}\right)\left[U^{+}\left(t_{0}\right)\right]$ is s-negative [s-positive] where $\Gamma(t) \in \Gamma_{1}(s)$, $s \in U^{+}\left(s_{0}\right)$. 
6. Lemma. Let $t_{0}$ be $s_{0}$-negative, $U^{+}\left(s_{0}\right) \leftrightarrow U^{-}\left(t_{0}\right)$ and each $t \in U^{-}\left(t_{0}\right)$ be s-negative where $\Gamma(t) \in \Gamma_{1}(s), s \in U^{+}\left(s_{0}\right)$. Let $\Gamma_{1}\left(s_{i}\right)$ cut $\Gamma$ at $t_{i} \in$ $U^{-}\left(t_{0}\right), i=1,2$. Then $s_{1}<s_{2}\left(s_{1}\right.$ precedes $\left.s_{2}\right)$ in $U^{+}\left(s_{0}\right)$ implies that $t_{2}<t_{1}$ in $U^{-}\left(t_{0}\right)$ and $\Gamma\left[s_{2}, t_{2}\right] \subset \Gamma\left[s_{1}, t_{1}\right]$.

We now present another characterization of singular points and give sufficient conditions for their existence. With that purpose, let $\mathfrak{T}$ and $\mathfrak{N}$ ' be open segments in $T$ such that $\Gamma(\Re) \cap \Gamma\left(\Re^{\prime}\right)=\varnothing$ and $\Gamma_{1}(s) \cap$ $\Gamma\left(\Re^{\prime}\right) \neq \varnothing$ for each $s \in \Re$. If each point $t \in \Re^{\prime}$ lies on a tangent of $\Re$ and $\Gamma(t) \in \Gamma_{1}(s) \cap \Gamma\left(\Re{ }^{\prime}\right), s \in \Re$, implies that $\Gamma_{1}(s)$ cuts $\Re^{\prime}$ at $t$ and $t$ is $s$-negative, we write $\mathfrak{K} \sim \mathfrak{K}^{\prime}$.

7. Theorem. Let $t_{0} \in T$. Then $t_{0}$ is singular if and only if there exists an $U\left(t_{0}\right)$ of minimum order such that both $U^{-}\left(t_{0}\right)$ and $U^{+}\left(t_{0}\right)$ are of order two and (with $T$ possibly reoriented) $U^{+}\left(t_{0}\right) \sim U^{-}\left(t_{0}\right)$.

Proof. Since $t_{0}$ is elementary, there exists a $V\left(t_{0}\right)$ of minimum order such that $V^{-}\left(t_{0}\right)$ and $V^{+}\left(t_{0}\right)$ are both of order two.

If $t_{0}$ is regular then $V\left(t_{0}\right)$ is of order two and $\left|\Gamma_{1}(t) \cap \Gamma\left(V\left(t_{0}\right)\right)\right|=1$ for $t \in V\left(t_{0}\right)$ by 1.7. Hence the sufficient condition follows.

If $t_{0}$ is an inflection or a cusp then $V\left(t_{0}\right)$ is of order three, $\mid \Gamma_{1}\left(t_{0}\right) \cap$ $\Gamma\left(V\left(t_{0}\right)\right) \mid=1$ and $\Gamma_{1}\left(t_{0}\right)$ meets, and cuts, $\Gamma$ at exactly $t_{0}$ in $V\left(t_{0}\right)$. Let $s \in V^{+}\left(t_{0}\right)$ tend to $t_{0}$. Then $\lim \Gamma_{1}(s)=\Gamma_{1}\left(t_{0}\right)$ by 1.3 and this readily implies that $\Gamma_{1}(s)$ meets, and cuts, $V^{-}\left(t_{0}\right)$ at exactly one point $t$ for sufficiently close to $s_{0}$. Hence there exist $W^{+}\left(t_{0}\right) \subseteq V^{+}\left(t_{0}\right)$ and $W^{-}\left(t_{0}\right)$ $\subset V^{-}\left(t_{0}\right)$ such that $W^{+}\left(t_{0}\right) \rightarrow W^{-}\left(t_{0}\right)$. By arguing as in the proof of 3.4, there exist $U^{+}\left(t_{0}\right) \subseteq W^{+}\left(t_{0}\right)$ and $U^{-}\left(t_{0}\right) \subseteq W^{-}\left(t_{0}\right)$ such that $U^{+}\left(t_{0}\right) \leftrightarrow$ $U^{-}\left(t_{0}\right)$. Since $t \in U^{-}\left(t_{0}\right)$ tends to $t_{0}$ as $s \in U^{+}\left(t_{0}\right)$ tends to $t_{0}$, it is immediate that each $t$ is $s$-negative.

If $t_{0}$ is a beak then $V\left(t_{0}\right)$ is of order two and $\Gamma_{1}\left(t_{0}\right)$ meets, and supports, $\Gamma$ at exactly $t_{0}$ in $V\left(t_{0}\right)$. It is easy to check that for all $s \in V^{+}\left(t_{0}\right)$ close to $t_{0}$, either $\Gamma_{1}(s) \cap \Gamma\left(V^{-}\left(t_{0}\right)\right)=\varnothing$ or $\Gamma_{1}(s)$ meets, and cuts, $V^{-}\left(t_{0}\right)$ at exactly two points. By reorienting $T$ if necessary, we may assume that $\left|\Gamma_{1}(s) \cap \Gamma\left(V^{-}\left(t_{0}\right)\right)\right|=2$ for $s \in V^{+}\left(t_{0}\right)$ close to $t_{0}$. Then by arguing as in the preceding, we obtain that there exist $U^{+}\left(t_{0}\right) \subseteq V^{+}\left(t_{0}\right)$ and $U^{-}\left(t_{0}\right) \subseteq V^{-}\left(t_{0}\right)$ such that each point of $U^{-}\left(t_{0}\right)$ lies on a tangent of $U^{+}\left(t_{0}\right)$ and every tangent of $U^{+}\left(t_{0}\right)$ cuts $U^{-}\left(t_{0}\right)$ at each point of contact. Then $\lim \left(\Gamma_{1}(s) \cap \Gamma\left(U^{-}\left(t_{0}\right)\right)\right)=\left\{\Gamma\left(t_{0}\right)\right\}$ as $s \in U^{+}\left(t_{0}\right)$ tends to $t_{0}$ implies that $U^{+}\left(t_{0}\right) \sim U^{-}\left(t_{0}\right)$. 
8. Lemma. Let $\Gamma\left(s_{0}, t_{0}\right)$ be simple. Let $U^{+}\left(s_{0}\right)=\left(s_{0}, s_{1}\right), s_{0} \neq s_{1}$, be the maximal (open right-neighbourhood of $s_{0}$ ) in $\left(s_{0}, t_{0}\right)$ such that there exists an $U^{-}\left(t_{0}\right)=\left(t_{1}, t_{0}\right)$ with $U^{+}\left(s_{0}\right) \sim U^{-}\left(t_{0}\right)$. Then $s_{1}=t_{1}$ or $\Gamma_{1}\left(s_{1}\right)$ supports $\Gamma$ at a point $t \in\left[t_{1}, t_{\theta}\right)$ or $s_{1}$ is a beak or an inflection point.

Proof. Let $\left(s_{0}, s_{1}\right) \sim\left(t_{1}, t_{0}\right), s_{1} \neq t_{1}$. Then for any $s_{2} \in\left(s_{1}, t_{1}\right)$ there is an $s \in\left(s_{0}, s_{2}\right)$ such that (1) $\Gamma_{1}(s) \cap \Gamma\left(t_{1}, t_{0}\right)=\varnothing$ or $(2) \Gamma_{1}(s)$ supports $\Gamma$ at a point $t \in\left(t_{1}, t_{0}\right)$ or (3) $\Gamma_{1}(s)$ cuts $\Gamma$ at a point $t \in\left(t_{1}, t_{0}\right)$ and $t$ is $s$-positive.

If (1) for any $s_{2} \in\left(s_{1}, t_{1}\right)$, then 1.3,3.3 and the hypotheses yield that $\Gamma_{1}\left(s_{1}\right) \cap \Gamma\left(t_{1}, t_{0}\right)=\varnothing$ and $\Gamma_{1}\left(s_{1}\right)$ supports $\Gamma$ at $t_{1}$. If (2) for any $s_{2} \in$ $\left(s_{1}, t_{1}\right)$, then $s \in\left[s_{1}, s_{2}\right)$ by the hypotheses and $\Gamma_{1}\left(s_{1}\right)$ supports $\Gamma$ at a point $t \in\left[t_{1}, t_{0}\right)$ by 1.3. If (3) for any $s_{2} \in\left(s_{1}, t_{1}\right)$, then again $s \in\left[s_{1}, s_{2}\right)$ and thus $\Gamma_{1}\left(s_{1}\right)$ cuts $\Gamma$ at a point $t \in\left[t_{1}, t_{0}\right)$ such that $t$ is $s_{1}$-positive. By the Corollary of $3.4, s_{1}$ is clearly a beak or an inflection.

ReMARK. Since $\left(s_{0}, s_{1}\right) \sim\left(t_{1}, t_{0}\right)$ implies that each tangent of $\left(s_{0}, s_{1}\right)$ meets $\left(t_{1}, t_{0}\right)$, the choice of $\left(t_{1}, t_{0}\right)$ in 3.8 is not arbitrary. In fact if $s_{1}$ is not singular, then $\left(t_{1}, t_{0}\right)$ is the maximal $U^{-}\left(t_{0}\right)$ in $\left(s_{0}, t_{0}\right)$ such that $\left(s_{0}, s_{1}\right) \sim\left(t_{1}, t_{0}\right)$. We also note that $\Gamma_{1}\left(s_{1}\right)$ supporting $\Gamma$ at a point $t \in\left[t_{1}, t_{0}\right)$ does not exclude $\Gamma_{1}\left(s_{1}\right)$ meeting $\Gamma$ at $t_{0}$ in some fashion.

9. LemMA. Let $\Gamma\left(s_{0}, t_{0}\right)$ be a simple subarc such that $t_{0}$ is $s_{0}$-negative and no tangent supports $\Gamma$ at more than one point. Then $\left(s_{0}, t_{0}\right)$ is not regular (contains a singular point).

Proof. By 3.5, there is a mximal $U^{+}\left(s_{0}\right)=\left(s_{0}, s_{1}\right)$ in $\left(s_{0}, t_{0}\right)$ such that $U^{+}\left(s_{0}\right) \sim U^{-}\left(t_{0}\right)$ for some $U^{-}\left(t_{0}\right)=\left(t_{1}, t_{0}\right) \subset\left(s_{1}, t_{0}\right)$. By 3.8, $s_{1}=t_{1}$ or $\Gamma_{1}\left(s_{1}\right)$ supports $\Gamma$ at some $t \in\left[t_{1}, t_{0}\right)$ or $s_{1}$ is singular.

If $s_{1}=t_{1}$, then $\left(s_{0}, t_{0}\right)=\left(s_{0}, s_{1}\right) \cup\left\{s_{1}\right\} \cup\left(s_{1}, t_{0}\right)$. Then $\left(s_{0}, s_{1}\right) \sim$ $\left(s_{1}, t_{0}\right)$ and 3.6 (with $T$ reoriented) imply that $s_{1}$ is singular. If $s_{1} \neq t_{1}$ and $\Gamma_{1}\left(s_{1}\right)$ supports $\Gamma$ at $t \in\left[t_{1}, t_{0}\right)$, then $\Gamma_{1}\left(s_{1}\right) \neq \Gamma_{1}(t)$ or $\Gamma_{1}\left(s_{1}\right)$ cuts $\Gamma$ at $s_{1}$ by the hypotheses. If $\Gamma_{1}\left(s_{1}\right) \neq \Gamma_{1}(t)$, then $t$ is a cusp or a beak. If $\Gamma_{1}\left(s_{1}\right)$ cuts $\Gamma$ at $s_{1}$, then $s_{1}$ is an inflection or a cusp.

10. Lemma. Let $\Gamma\left(s_{0}, t_{0}\right)$ be a subarc such that $t_{0}$ is $s_{0}$-negative and $\Gamma_{1}\left(s_{0}\right) \cap \Gamma\left(s_{0}, t_{0}\right)=\varnothing$. Then $\left(s_{0}, t_{0}\right)$ is not regular.

Proof. Since $\Gamma$ is almost-simple, $\Gamma\left(s_{0}, t_{0}\right)$ is simple and we may assume that 3.9 does not apply to $\Gamma\left(s_{0}, t_{0}\right)$. 
Since $\Gamma$ is elementary, 3.5 implies there exist $V^{+}\left(s_{0}\right)$ and $V^{-}\left(t_{0}\right)$, both of order two, in $\left(s_{0}, t_{0}\right)$ such that $V^{+}\left(s_{0}\right) \sim V^{-}\left(t_{0}\right)$. Let $s \in V^{+}\left(s_{0}\right)$. Then $\Gamma_{1}(s) \cap \Gamma\left(s, t_{0}\right) \neq \varnothing$ and there is a $t \in\left(s, t_{0}\right)$ such that $\Gamma_{1}(s) \cap$ $\Gamma(s, t]=\{\Gamma(t)\}$. By 1.3 and 1.7, $\Gamma_{1}\left(s_{0}\right) \cap \Gamma\left(s_{0}, t_{0}\right)=\varnothing$ clearly implies that $t$ tends to $t_{0}$ as $s$ tends to $s_{0}$. Hence we may assume that $t \in V^{-}\left(t_{0}\right)$ (hence $t$ is $s$-negative) for $s \in V^{+}\left(s_{0}\right)$ arbitrarily close to $s_{0}$. Let $s^{\prime}>s$ be arbitrarily close to $s_{0}$ in $V^{+}\left(s_{0}\right)$. Then $\Gamma_{1}\left(s^{\prime}\right)$ cuts $\Gamma$ at a point $t^{\prime} \in V^{-}\left(t_{0}\right)$ such that $\Gamma_{1}\left(s^{\prime}\right) \cap \Gamma\left(s^{\prime}, t^{\prime}\right)=\varnothing$ and by $3.6,\left(s^{\prime}, t^{\prime}\right) \subset(s, t) \subset\left(s_{0}, t_{0}\right)$.

It is now immediate that there is a maximal $U^{+}\left(s_{0}\right)=\left(s_{0}, s_{1}\right)$ in $\left(s_{0}, t_{0}\right)$ such that $\left(s_{0}, s_{1}\right)$ is regular and for each $s \in\left(s_{0}, s_{1}\right), \Gamma_{1}(s)$ cuts $\Gamma$ at a point $t \in\left(s, t_{0}\right)$ such that $t$ is $s$-negative and $\Gamma_{1}(s) \cap \Gamma(s, t)=\varnothing$. Let $t_{1}^{\prime}$ be an accumulation point of $t$ as $s \in\left(s_{0}, s_{1}\right)$ tends to $s_{1}$. By 1.3 and 3.6, $\Gamma\left(t_{1}^{\prime}\right) \subset \Gamma_{1}\left(s_{1}\right)$ and $t \in\left(t_{1}^{\prime}, t_{0}\right)$ for $s \in\left(s_{0}, s_{1}\right)$. Hence $t^{\prime}$ is the limit point of $t$. (At this point, one should note that we do not claim that $\left(s_{0}, s_{1}\right) \sim\left(t_{1}^{\prime}, t_{0}\right)$. We are only concerned with how $\Gamma_{1}\left(s_{1}\right)$ meets $\Gamma\left(s_{1}, t_{1}^{\prime}\right]$. $)$ From the maximality of $\left(s_{0}, s_{1}\right)$, it readily follows that either $s_{1}$ is singular or $s_{1} \neq t_{1}^{\prime}$ and $\Gamma_{1}\left(s_{1}\right)$ supports $\Gamma$ at $t_{1}^{\prime}$ or $\Gamma_{1}\left(s_{1}\right) \cap \Gamma\left(s_{1}, t_{1}^{\prime}\right) \neq \varnothing$. Assuming that $s_{1}$ is regular, $s_{1} \neq t_{1}^{\prime}$ and $\Gamma_{1}\left(s_{1}\right)$ supporting $\Gamma$ at $t_{1}^{\prime}$ also yield that $\Gamma_{1}\left(s_{1}\right) \cap \Gamma\left(s_{1}, t_{1}^{\prime}\right) \neq \varnothing$. Clearly $\Gamma_{1}\left(s_{1}\right)$ supports $\Gamma\left(s_{1}, t_{1}^{\prime}\right)$ at each point of contact and there is a $t_{1} \in\left(s_{1}, t_{1}^{\prime}\right)$ such that $\Gamma_{1}\left(s_{1}\right) \cap \Gamma\left(s_{1}, t_{1}\right]=\left\{\Gamma\left(t_{1}\right)\right\}$. Then $s_{1}$ regular and $\left(s_{0}, s_{1}\right)$ maximal imply that $t_{1}$ is both $s_{1}$-positive and $s_{1}$-negative. We note that if $\Gamma_{1}\left(s_{1}\right) \neq \Gamma_{1}\left(t_{1}\right)$, then $t_{1}$ is a beak or a cusp.

In summary, $\left(s_{0}, t_{0}\right)$ is not regular or there exist $s_{1}<t_{1}$ in $\left(s_{0}, t_{0}\right)$ such that $t_{1}$ is $s_{1}$-negative, $\Gamma_{1}\left(s_{1}\right) \cap \Gamma\left(s_{1}, t_{1}\right)=\varnothing$ and $\Gamma_{1}\left(s_{1}\right)$ is a multiple tangent supporting $\Gamma\left(s_{0}, t_{0}\right)$ at least twice.

By reiteration of the preceding arguments and 1.1, there exist $\bar{s}<\bar{t}$ in $\left(s_{1}, t_{1}\right) \subset\left(s_{0}, t_{0}\right)$ such that $\bar{t}$ is $\bar{s}$-negative, $\Gamma_{1}(\bar{s}) \cap \Gamma(\bar{s}, \bar{t})=\varnothing$ and $\Gamma(\bar{s}, \bar{t})$ possesses no multiple tangents. Then either the lemma follows by 3.9 or there exist $s^{\prime}<t^{\prime}$ in $(\bar{s}, \bar{t})$ such that $\Gamma_{1}\left(s^{\prime}\right)$ supports $\Gamma$ at $t^{\prime}$. If $s^{\prime}$ is regular, then $\Gamma_{1}\left(s^{\prime}\right) \neq \Gamma_{1}\left(t^{\prime}\right)$ and $t^{\prime}$ is singular.

Let $\Gamma\left(t_{1}, t_{2}\right)$ be a subarc of order two. By 1.7, $\left|\Gamma_{1}(t) \cap \Gamma\left[t_{1}, t_{2}\right]\right|=1$ for $t \in \Gamma\left(t_{1}, t_{2}\right)$ and thus there is an $L \subset P^{2}$ such that $L \cap \Gamma\left[t_{1}, t_{2}\right]=0$ and $\Gamma\left[t_{1}, t_{2}\right]$ is simple. Lety $H\left(\Gamma\left[t_{1}, t_{2}\right]\right)$ be the convex hull of $\Gamma\left[t_{1}, t_{2}\right]$ (in $\left.P^{2} \backslash L\right)$. Then $R=H\left(\Gamma\left[t_{1}, t_{2}\right]\right)$ is the closed region in $P^{2}$ bounded by $\Gamma\left[t_{1}, t_{2}\right]$ and $\left\langle\Gamma\left(t_{1}\right), \Gamma\left(t_{2}\right)\right\rangle$ such that $\left|\Gamma_{1}(t) \cap \Re\right|=1$ for $t \in\left(t_{1}, t_{2}\right)$. We note that any line through any point of int( $\Re)$ meets $\Gamma\left(t_{1}, t_{2}\right)$ at least once.

The following result should be well-known.

11. Lemma. Let $\Gamma\left(t_{1}, t_{2}\right)$ be a regular subarc such that $\Gamma_{1}\left(t_{1}\right) \cap \Gamma\left(t_{1}, t_{2}\right]$ $=\left\{\Gamma\left(t_{2}\right)\right\}$. Then $\Gamma\left(t_{1}, t_{2}\right)$ is of order two. 
Proof. $\Gamma\left[t_{1}, t_{2}\right]$ is clearly simple. As $\left(t_{1}, t_{2}\right)$ is regular, $\Gamma_{1}\left(t_{1}\right) \cap$ $\Gamma\left(t_{1}, t_{2}\right)=\varnothing$ and 3.10 imply that $t_{2}$ is not $t_{1}$-negative. Then $t_{1}$ elementary, 1.7, 3.5 and 1.3 readily yield that there exists a maximal $U^{+}\left(t_{1}\right)=$ $\left(t_{1}, s_{1}\right)$ in $\left(t_{1}, t_{2}\right)$ such that $\left|\Gamma_{1}(s) \cap \Gamma\left[t_{1}, t_{2}\right]\right|=1$ for $s \in\left(t_{1}, s_{1}\right)$. If $s_{1}=t_{2}$, the lemma follows by 1.6 .

Suppose $s_{1} \neq t_{2}$. Then $\Gamma(t) \in \Gamma_{1}\left(s_{1}\right)$ for some $t \neq s_{1}$ in $\left[t_{1}, t_{2}\right]$. If $t \in\left(t_{1}, t_{2}\right)$, then clearly $\Gamma_{1}\left(s_{1}\right)$ supports $\Gamma$ at $t$ and $t$ is both $s_{1}$-positive and $s_{1}$-negative. By the maximality of $\left(t_{1}, s_{1}\right), t \notin\left(t_{1}, s_{1}\right)$ and hence we may assume that $\Gamma_{1}\left(s_{1}\right) \cap \Gamma\left(s_{1}, t\right)=\varnothing$. As $t$ is $s_{1}$-negative, 3.10 implies that $\left(s_{1}, t\right) \subset\left(t_{1}, t_{2}\right)$ is not regular, a contradiction. Hence $t \in\left\{t_{1}, t_{2}\right\}$ and $\Gamma_{1}\left(s_{1}\right) \cap \Gamma\left(t_{1}, t_{2}\right)=\left\{\Gamma\left(s_{1}\right)\right\}$.

Suppose $\Gamma\left(t_{2}\right) \in \Gamma_{1}\left(s_{1}\right)$ and choose $U^{-}\left(t_{2}\right) \subset\left(s_{1}, t_{1}\right)$. Then $\Gamma_{1}(s) \cap$ $\Gamma\left(U^{-}\left(t_{2}\right)\right)=\varnothing$ for $s \in\left(t_{1}, s_{1}\right)$ yields that $t_{2}$ is $s_{1}$-negative [ $s_{1}$-negative and $s_{1}$-positive] if $\Gamma_{1}\left(s_{1}\right)$ cuts [supports] $\Gamma$ at $s_{2}$. Hence $\left(s_{1}, t_{2}\right)$ is not regular by 3.10 , a contradiction.

Suppose $\Gamma_{1}\left(s_{1}\right) \cap \Gamma\left[t_{1}, t_{2}\right]=\left\{\Gamma\left(t_{1}\right), \Gamma\left(s_{1}\right)\right\}$. Then $\Gamma\left(t_{1}, s_{1}\right)$ is of order to by 1.6. Let $\mathscr{R}=H\left(\Gamma\left[t_{1}, s_{1}\right]\right.$ ) (in $P^{2} \backslash L, L \cap \Gamma\left[t_{1}, s_{1}\right]=\varnothing$ ). Since $\Gamma_{1}\left(t_{1}\right) \cap \Gamma\left(t_{1}, s_{1}\right)=\varnothing, \quad \Gamma\left(t_{2}\right) \in \Gamma_{1}\left(t_{1}\right)$ yields that $\Gamma\left(t_{2}\right) \notin \Re$. But $s_{1}$ ordinary implies there is an $U\left(s_{1}\right) \subset\left(t_{1}, t_{2}\right)$ of order two. Then $\Gamma\left(U^{-}\left(s_{1}\right)\right)$ $\subset$ bd $(\Re)$ and 1.7 imply that $\Gamma_{1}(s) \cap \Gamma\left(U^{+}\left(s_{1}\right)\right)=\varnothing$ for $s \in U^{-}\left(s_{1}\right)$ and $\Gamma\left(U^{+}\left(s_{1}\right)\right) \subset \operatorname{int}(\Re)$. Thus $\operatorname{bd}(\Re) \cap \Gamma\left(s_{1}, t_{2}\right) \neq \varnothing$. Then $\operatorname{bd}(\Re) \subset$ $\Gamma\left[t_{1}, s_{1}\right] \cup \Gamma_{1}\left(s_{1}\right)$ and $\Gamma\left[t_{1}, t_{2}\right]$ simple imply that $\Gamma_{1}\left(s_{1}\right) \cap \Gamma\left(s_{1}, t_{2}\right) \neq \varnothing$, a contradiction.

12. Lemma. Let $\Gamma\left(t_{1}, t_{2}\right)$ be simple. Let $s_{1} \in\left(t_{1}, t_{2}\right)$ such that $\Gamma_{1}\left(s_{1}\right) \cap$ $\Gamma\left[t_{1}, t_{2}\right]=\left\{\Gamma\left(t_{1}\right), \Gamma\left(s_{1}\right), \Gamma\left(t_{2}\right)\right\}$. Then $\left(t_{1}, t_{2}\right)$ is not regular.

Proof. We assume that $\left(t_{1}, s_{1}\right]$ is regular. Then $\Gamma_{1}\left(s_{1}\right) \cap \Gamma\left(t_{1}, s_{1}\right)=\varnothing$ yields that $\Gamma\left[t_{1}, s_{1}\right]$ is simple and by $3.11, \Gamma\left(t_{1}, s_{1}\right)$ is of order two. Let $\Re=H\left(\Gamma\left[t_{1}, s_{1}\right]\right)$. Arguing as in the proof of 3.11 , we observe that $\Gamma_{1}\left(s_{1}\right)$ $\cap \Gamma\left(s_{1}, t_{2}\right]=\left\{\Gamma\left(t_{2}\right)\right\}$ implies that (cf. Figure 2) $\Gamma\left[s_{1}, t_{2}\right] \subset \Re, \Gamma\left[s_{1}, t_{2}\right]$ is simple and $t_{2}$ is $s_{1}$-negative. Hence by $3.10,\left(s_{1}, t_{2}\right) \subset\left(t_{1}, t_{2}\right)$ is not regular.

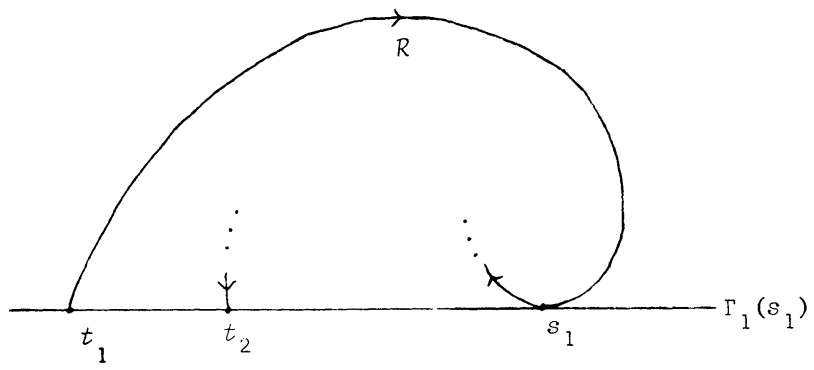

Figure 2 
Before proceeding with the proof of Theorem 3.1, we still need to investigate the regular simple subarcs of $\Gamma$.

13. LemMA. Let $\Gamma\left(t_{1}, t_{2}\right)$ be a regular, simple subarc such that $\left\langle\Gamma\left(t_{1}\right), \Gamma\left(t_{2}\right)\right\rangle \cap \Gamma\left(t_{1}, t_{2}\right)=\varnothing$. Then $\Gamma\left(t_{1}, t_{2}\right)$ is of order two.

Proof. Suppose there is an $s \in\left(t_{1}, t_{2}\right)$ such that $\Gamma\left(t_{2}\right) \in \Gamma_{1}(s)$. Then there is an $s^{\prime} \in\left(s, t_{2}\right]$ such that $\Gamma_{1}(s) \cap \Gamma\left(s, s^{\prime}\right)=\left\{\Gamma\left(s^{\prime}\right)\right\}$. Then $\Gamma\left(s, s^{\prime}\right)$ is of order two by 3.11 and $\Gamma_{1}(s) \cap \Gamma\left[t_{1}, s\right)=\varnothing$ by 3.12. Hence $\Gamma\left(t_{1}\right) \in$ $\operatorname{int}\left(H\left(\Gamma\left[s, s^{\prime}\right]\right)\right)$ from the proof of 3.11. But then $\left\langle\Gamma\left(t_{1}\right), \Gamma\left(t_{2}\right)\right\rangle \cap \Gamma\left(s, s^{\prime}\right)$ $\neq \varnothing$, a contradiction. The lemma now follows by 1.6.

14. LeMma. Let $\Gamma\left(t_{1}, t_{2}\right)$ be regular and simple. Then

(1) there is a $t \in\left(t_{1}, t_{2}\right)$ such that $\left|\Gamma_{1}(t) \cap \Gamma\left[t_{1}, t_{2}\right]\right|=1$ and

(2) there is an $L$ such that $L \cap \Gamma\left[t_{1}, t_{2}\right]=\varnothing$.

Proof. Clearly (1) implies (2).

If $\Gamma_{1}\left(t_{1}\right) \cap \Gamma\left(t_{1}, t_{2}\right]=\varnothing$ then $t_{1}$ elementary, 1.7, 1.3, and 1.5 imply that there is a $t \in\left(t_{1}, t_{2}\right)$, arbitrarily close to $t_{1}$, such that $\mid \Gamma_{1}(t) \cap$ $\Gamma\left[t_{1}, t_{2}\right] \mid=1$.

Let $\Gamma_{1}\left(t_{1}\right) \cap \Gamma\left(t_{1}, t_{2}\right) \neq \varnothing$. Then there is an $s_{1} \in\left(t_{1}, t_{2}\right]$ such that $\Gamma_{1}\left(t_{1}\right) \cap \Gamma\left(t_{1}, s_{1}\right]=\left\{\Gamma\left(s_{1}\right)\right\}$. By 3.11, $\Gamma\left(t_{1}, s_{1}\right)$ is of order two, $\Gamma\left[t_{1}, s_{1}\right]$ is simple and (1) follows if $s_{1}=t_{2}$. Let $s_{1} \neq t_{2}$. If $\Gamma_{1}\left(t_{1}\right)$ supports $\Gamma$ at $s_{1}$ then $\Gamma_{1}\left(t_{1}\right)=\Gamma_{1}\left(s_{1}\right)$ and by 3.12, $\Gamma_{1}\left(s_{1}\right) \cap \Gamma\left(s_{1}, t_{2}\right]=\varnothing$. Hence (cf. the proofs of 3.11 and 3.12) $\Gamma\left(s_{1}, t_{2}\right] \subset H\left(\Gamma\left[t_{1}, s_{1}\right]\right)$ and any $t \in\left(t_{1}, s_{1}\right)$ satisfies (1).

Let $\Gamma_{1}\left(t_{1}\right)$ cut $\Gamma$ at $s_{1}$. Then $s_{1}$ is $t_{1}$-positive by 3.10. Since $\Gamma_{1}\left(t_{1}\right) \cap$ $\Gamma\left(t_{1}, s_{1}\right)=\varnothing, 3.5$ and 3.12 imply that there exist

(a) $t \in\left(t_{1}, t_{2}\right)$, arbitrarily close to $t_{1}$, such that $\Gamma_{1}(t)$ cuts $\Gamma$ at a point $s \in\left(s_{1}, t_{2}\right) \subset\left(t_{1}, t_{2}\right)$ where $\Gamma_{1}(t) \cap \Gamma(t, s)=\varnothing, s$ is $t$-positive and $\Gamma_{1}(t)$ $\cap \Gamma\left[t_{1}, t\right)=\varnothing$.

The preceding argument is symmetric in $t_{1}$ and $t_{2}$ with the orientation of $T$ reversed; that is, we may assume that there is an $s_{2} \in\left(t_{1}, t_{2}\right)$ such that $\Gamma_{1}\left(t_{2}\right)$ cuts $\Gamma$ at $s_{2}, \Gamma_{1}\left(t_{2}\right) \cap \Gamma\left(s_{2}, t_{2}\right)=\varnothing$ and $t_{2}$ is $s_{2}$-negative. Then there eixst

(b) $t \in\left(t_{1}, t_{2}\right)$, arbitrarily close to $t_{2}$, such that $\Gamma_{1}(t)$ cuts $\Gamma$ at a point $s \in\left(t_{1}, s_{2}\right) \subset\left(t_{1}, t_{2}\right), \Gamma_{1}(t) \cap \Gamma(s, t)=\varnothing, s$ is $t$-negative and $\Gamma_{1}(t) \cap$ $\Gamma\left(t, t_{2}\right]=\varnothing$.

Since either $\Gamma_{1}(t) \cap \Gamma\left[t_{1}, t\right)=\varnothing$ or $\Gamma_{1}(t) \cap \Gamma\left(t, t_{2}\right]=\varnothing$ for any $t \in\left(t_{1}, t_{2}\right)$ by 3.12 , (1) readily follows from (a), (b) and 1.3 . 
15. Lemma. Let $\Gamma\left(t_{1}, t_{2}\right)$ be regular and simple. Then there exist $s_{1}<s_{2}$ in $\left[t_{1}, t_{2}\right]$ such that $\Gamma\left(s_{1}, s_{2}\right)$ is of order two and $\Gamma\left[t_{1}, t_{2}\right] \subset H\left(\Gamma\left[s_{1}, s_{2}\right]\right)$.

Proof. By 3.14, there is a $\bar{t} \in\left(t_{1}, t_{2}\right)$ such that $\left|\Gamma_{1}(\bar{t}) \cap \Gamma\left[t_{1}, t_{2}\right]\right|=1$. Since $\bar{t}$ is ordinary, 1.7 and 1.3 imply that there is a maximal $U(\bar{t})=\left(s_{1}, s_{2}\right)$ of order two in $\left(t_{1}, t_{2}\right)$ such that $\left|\Gamma_{1}(t) \cap \Gamma\left[t_{1}, t_{2}\right]\right|=1$ for $t \in\left(s_{1}, s_{2}\right)$.

Let $\Re=H\left(\Gamma\left[s_{1}, s_{2}\right]\right)$. If $s_{2} \neq t_{2}$, then $\Gamma_{1}\left(s_{2}\right)$ meets either $\Gamma\left(s_{2}, t_{2}\right]$ or $\Gamma\left[t_{1}, s_{1}\right]$ by 3.12. From the proof of 3.11, we obtain that $\Gamma_{1}\left(s_{2}\right) \cap \Gamma\left(s_{2}, t_{2}\right]$ $=\varnothing$ and hence there is a $t \in\left[t_{1}, s_{1}\right]$ such that $\Gamma_{1}\left(s_{2}\right) \cap \Gamma\left[t, s_{2}\right)=\{\Gamma(t)\}$. If $t=t_{1}$, then clearly $t_{1}=s_{1}$ and $\Gamma\left[t_{1}, t_{2}\right] \subset H\left(\Gamma\left[t_{1}, s_{2}\right]\right)=\Re$. If $t \neq t_{1}$ then $\Gamma_{1}\left(s_{2}\right)=\Gamma_{1}(t)$ and by 3.12, $\Gamma_{1}\left(s_{2}\right) \cap \Gamma\left[t_{1}, t\right)=\varnothing$. Since $\Gamma_{1}\left(s_{2}\right)$ supports $\Gamma$ at $t$, we again obtain from the proof of 3.11 that $t=s_{1}$ and $\Gamma\left[t_{1}, t_{2}\right] \subset \Re$.

The preceding argument is symmetric in $s_{1}$ and $s_{2}$.

We call $\Gamma\left[s_{1}, s_{2}\right]$ in 3.15 , the convex cover of $\Gamma\left[t_{1}, t_{2}\right]$. We note that Lemmas 3.13-3.15 are known in some form or another. The proofs have been included for the sake of completeness and because the approach is new.

Since $\Gamma$ is of even order with positive index, we observe:

16. Lemma. If $L$ supports $\Gamma$ at a simple point, then $L$ meets $\Gamma$ at three distinct points of $T$.

17. Lemma. Let $\Gamma\left(t_{1}, t_{2}\right)$ be simple and regular. Let $L \cap \Gamma\left[t_{2}, t_{1}\right]=\varnothing$. Then $L$ meets, and cuts, $\Gamma$ at exactly two points, at least one of which lies in the convex cover of $\Gamma\left[t_{1}, t_{2}\right]$.

Proof. Let $\Gamma\left[s_{1}, s_{2}\right]$ be the convex cover of $\Gamma\left[t_{1}, t_{2}\right], \mathcal{R}=H\left(\Gamma\left[s_{1}, s_{2}\right]\right)$. Then ind $(\Gamma)>0$ and $L \cap \Gamma\left[t_{2}, t_{1}\right]=\varnothing$ imply that $L \cap \Re \neq \varnothing$. Since $\Gamma\left[t_{1}, t_{2}\right] \subset \Re$ is simple, $\left|L \cap \Gamma\left(t_{1}, t_{2}\right)\right| \geq 2$ by 3.16 and $L$ separates $\Re$ into two closed regions $\Re_{1}$ and $\Re_{2}$ such that $\Re_{1} \cup \Omega_{2}=\Re$ and $\Re_{1} \cap R_{2}=$ $L \cap \Re$. Since $\Gamma$ is of even order, $L$ cuts $\Gamma\left(t_{1}, t_{2}\right)$ at an even number of points and thus $\left\{\Gamma\left(t_{1}\right), \Gamma\left(t_{2}\right)\right\} \subset \Re_{1}$ say.

We first observe that if $L$ meets $\Gamma\left(t_{1}, t_{2}\right)$ in less than three points, then $L$ cuts $\Gamma\left(t_{1}, t_{2}\right)$ exactly twice by 3.16 . If $\left|L \cap \Gamma\left(t_{1}, t_{2}\right)\right| \geq 3$, then $L$ supports $\Gamma\left(t_{1}, t_{2}\right)$ at most once by 3.12 .

Suppose that $\left|L \cap \Gamma\left(t_{1}, t_{2}\right)\right| \geq 3$. Then $\Re_{2}$ convex implies that $\operatorname{int}\left(\Re_{2}\right) \cap \Gamma\left(t_{1}, t_{2}\right) \neq \varnothing$. Let $\Gamma(s) \in\left(\Re_{2} \cap \Gamma\left(s_{1}, s_{2}\right)\right) \backslash L$. Then $\Gamma_{1}(s) \cap$ $\operatorname{int}(\Re)=\varnothing$ and $\Gamma_{1}(s)$ meets $L \backslash \Re$ at a point $p$. We note that $\Re_{1}$ and $\Re_{2}$ are contained in the different closed half-planes bounded by $\Gamma_{1}(s)$ and $L$. 
Hence $\Gamma_{1}(s) \cap \operatorname{int}\left(\Re_{2}\right)=\varnothing$ and $\Gamma\left(t_{1}, t_{2}\right) \cap \operatorname{int}\left(\Re_{2}\right) \neq \varnothing$ imply that there is a line $N$ such that $p \in N, N \cap \Re_{1}=\varnothing$ and either (a) $N$ supports $\Gamma$ at some $t \in\left(t_{1}, t_{2}\right) \backslash\left(s_{1}, s_{2}\right)$ or (b) $\Gamma\left(t_{1}\right)$ or $\Gamma\left(t_{2}\right)$ lie on $L$. Suppose (a) and $t \in\left(t_{1}, s_{1}\right)$ say. Then $\Gamma(t) \in \operatorname{int}(\Re)$ and $\left(s_{1}, s_{2}\right) \subset\left(t_{1}, s_{2}\right)$ imply there is a $t^{\prime} \in\left(t, s_{2}\right)$ such that $\Gamma\left(t^{\prime}\right) \in N=\Gamma_{1}(t)$ and $\Gamma_{1}(t) \cap \Gamma\left(t, t^{\prime}\right)=\varnothing$. By $3.11, \Gamma\left(t, t^{\prime}\right)$ is of order two.

Let $\Re^{\prime}=H\left(\Gamma\left[t, t^{\prime}\right]\right)$. We note that $\Gamma_{1}(t) \cap \Gamma\left[t_{1}, t\right)=\varnothing$ by 3.12 and thus $\Gamma\left(t_{1}\right) \in \operatorname{int}\left(\Re^{\prime}\right)$ (cf. the proof of 3.11). Since $L$ separates $\Gamma(t)$ and $\Gamma\left(t_{1}\right)$ in $\Re, L$ also separates $\Gamma(t)$ and $\Gamma\left(t_{1}\right)$ in $\Re^{\prime}$. Let $\Re_{1}^{\prime}$ and $\Omega_{2}^{\prime}$ be the closed regions of $\Re^{\prime}$ determined by $L, \Gamma\left(t_{1}\right) \in \Omega_{1}^{\prime}$ and $\Gamma(t) \in \Omega_{2}^{\prime}$ say. The $\Re^{\prime} \cap \Re_{1}=\Re_{1}^{\prime}, i=1$, 2. Since $L \cap N=\{p\} \nsubseteq \mathscr{R}, L \cap N \cap \Re^{\prime}=$ $\varnothing$ and $N=\left\langle\Gamma(t), \Gamma\left(t^{\prime}\right)\right\rangle$ yield that there exist $r<r^{\prime}$ in $\left(t, t^{\prime}\right)$ such that $\Re_{1}^{\prime}$ is bounded by $\Gamma\left[r, r^{\prime}\right]$ and $L$. Finally we observe that 3.14 and $\Re=H\left(\Gamma\left[s_{1}, s_{2}\right]\right)$ imply that there is an $L^{\prime}$ such that $L^{\prime} \cap \Re=\varnothing$.

Then ind $(\Gamma)>0$ and $\Re_{1}^{\prime} \subset \Re^{\prime} \subset \Re$ imply that $\Gamma\left[t_{2}, t_{1}\right] \nsubseteq \Re_{1}^{\prime}$. Hence $\Gamma\left(t_{1}\right) \in \mathcal{R}_{1}^{\prime}$ and $L \cap \Gamma\left[t_{2}, t_{1}\right]=\varnothing$ yield that there exist $r^{*} \in\left(r, r^{\prime}\right) \subset$ $\left(t_{1}, t_{2}\right)$ and $t^{*} \in\left(t_{2}, t_{1}\right)$ such that $\Gamma\left(r^{*}\right)=\Gamma\left(t^{*}\right)$ and $\Gamma\left[t^{*}, t_{1}\right] \subset \Re_{1}^{\prime}$. Then $\Gamma\left[t^{*}, r^{*}\right]=\Gamma\left[t^{*}, t_{1}\right] \cup \Gamma\left[t_{1}, r^{*}\right] \subset \Re$ and $L^{\prime} \cap \Re=\varnothing$ imply that $\gamma$ is not almost-simple. Similarly $N \cap\left(\left(t_{1}, s_{1}\right) \cup\left(s_{2}, t_{2}\right)\right)=\varnothing,(\mathrm{b})$ and $\operatorname{ind}(\Gamma)>0$ imply that $\Gamma$ is not almost-simple, a contradiction.

COROLlary. Let $\Gamma\left(t_{1}, t_{2}\right]$ be simple and regular. Let $L=\lim L_{\lambda}$ where $L_{\lambda} \cap \Gamma\left[t_{2}, t_{1}\right]=\varnothing$ for each $L_{\lambda}$. Then $L$ cuts $\Gamma$ in at most two points.

Proof of Theorem 3.1. (i). If $\Gamma$ is simple, then ind $(\Gamma)>0$ implies that $\Gamma(T \backslash\{t\})$ contains a singular point for any $t \in T$ by 3.14 . Hence $n(\Gamma) \geq 2$.

If there exist $r_{1} \neq r_{2}$ in $T$ such that $\Gamma\left(r_{1}\right)=\Gamma\left(r_{2}\right)$, then 1.3 implies that there exist $t_{1}<t_{2}$ in $\left[r_{1}, r_{2}\right]$ and $s_{2}<s_{1}$ in $\left[r_{2}, r_{1}\right]$ such that $\Gamma\left(t_{1}\right)=$ $\Gamma\left(t_{2}\right), \Gamma\left(s_{2}\right)=\Gamma\left(s_{1}\right)$ and both $\Gamma\left(t_{1}, t_{2}\right)$ and $\Gamma\left(s_{2}, s_{1}\right)$ are simple. As $\Gamma$ is almost-simple, every line in $P^{2}$ meets both $\Gamma\left[t_{1}, t_{2}\right]$ and $\Gamma\left[s_{2}, s_{1}\right]$. Hence neither $\left(t_{1}, t_{2}\right)$ nor $\left(s_{2}, s_{1}\right)$ are regular by 3.14 and $n(\Gamma) \geq 2$.

Proof of Theorem 3.1 (ii). By 3.1 (i), $\Gamma$ contains at least two singular points $t_{1}$ and $t_{2}$. If $t_{1}$ and $t_{2}$ are both cusps, then $n_{1}+2 n_{2}+n_{3} \geq 2 n_{2} \geq 4$. For the curve represented in Figure $3, n_{1}=n_{3}=0$ and $n_{2}=2$.

If say only $t_{1}$ is a cusp, then $\Gamma$ contains a beak or an inflection point $t_{3} \neq t_{2}$ by 1.2. Therefore $n_{1}+2 n_{2}+n_{3} \geq 2+n_{1}+n_{3} \geq 4$. For the curve represented in Figure $4, n_{1}=n_{2}=n_{3}=1$. 


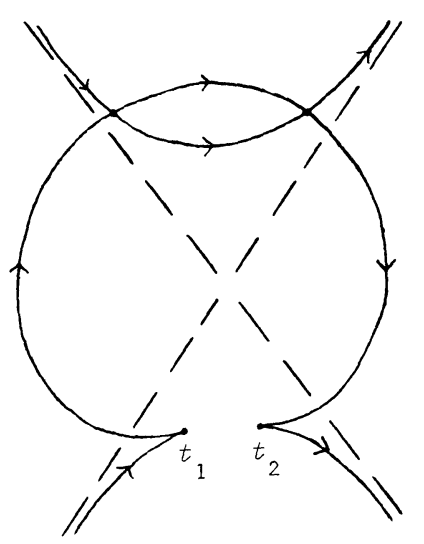

Figure 3

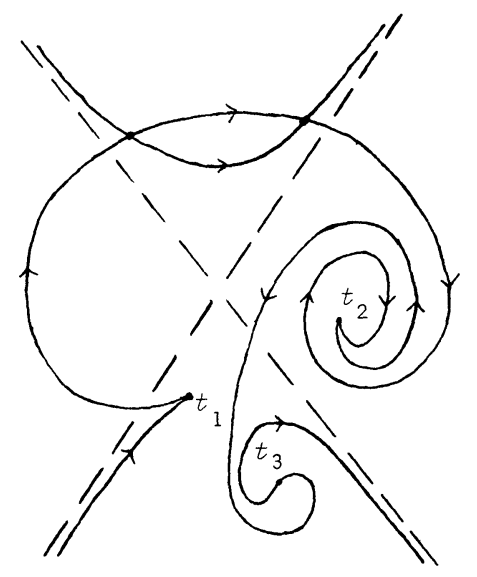

Figure 4

If $n_{2}=0$ and $n(\Gamma)=n_{1}+n_{3} \neq 2$, then $n(\Gamma) \geq 4$ by 1.2 . Hence we show that $n(\Gamma)=2$ implies that $n_{2}>0$. Let $\left(t_{1}, t_{2}\right)$ and $\left(t_{2}, t_{1}\right)$ be regular. Then $\Gamma\left[t_{1}, t_{2}\right]$ and $\Gamma\left[t_{1}, t_{2}\right]$ are simple from the proof of 3.1 (i). By 3.15, there exist points $t_{1} \leq s_{1}<s_{2} \leq t_{2} \leq u_{2}<u_{1} \leq t_{1}$ such that $\Gamma\left[t_{1}, t_{2}\right] \subset \Re_{1}$ $=H\left(\Gamma\left[s_{1}, s_{2}\right]\right)$ and $\Gamma\left[t_{2}, t_{1}\right] \subset \Re_{2}=H\left(\Gamma\left[u_{2}, u_{1}\right]\right)$. Let $L_{1}=$ $\left\langle\Gamma\left(s_{1}\right), \Gamma\left(s_{2}\right)\right\rangle$ and $L_{2}=\left\langle\Gamma\left(u_{2}\right), \Gamma\left(u_{1}\right)\right\rangle$. By 3.17 Corollary, $L_{2}$ and $L_{2}$ each cut $\Gamma$ at most twice.

We observe that $\Gamma\left[t_{1}, t_{2}\right] \subset \Re_{1}$ and $\operatorname{ind}(\Gamma)>0$ imply that $\Gamma\left[t_{2}, t_{1}\right] \not$ $\Re_{1}$. Hence there exist $v_{2}<v_{1}$ in $\left[t_{2}, t_{1}\right]$ such that $\Gamma\left[v_{1}, v_{2}\right]$ is the largest subarc of $\Gamma$ contained in $R_{1}$. As $\Gamma$ is almost-simple, $\Gamma\left[v_{1}, v_{2}\right]$ is simple.

Case 1. $s_{1}=t_{1}$ and $L_{1}$ supports $\Gamma$ at $s_{1}$.

Then $t_{1}$ is a cusp or a beak and we may assume that $t_{1}$ is a beak.

Suppose that $L_{1}$ supports $\Gamma$ at $s_{2} \neq t_{2}$. Then clearly $\Gamma\left(t_{2}\right) \in \operatorname{int}\left(\Re_{1}\right)$, $v_{2} \neq t_{2}, L_{1}$ cuts $\Gamma$ at $v_{2}\left(\Gamma\left[v_{1}, v_{2}\right]\right.$ is simple $)$ and $L_{1} \neq \Gamma_{1}\left(v_{2}\right)$. Since $L_{1}$ 
does not cut $\Gamma$ at any point of $\left[t_{1}, v_{2}\right)$ and $\Gamma$ is of even order, $L_{1}$ cuts $\Gamma$ at a point $t^{\prime} \in\left(v_{2}, t_{1}\right)$. We note that $L_{1}$ cuts $\Gamma$ at exactly $v_{2}$ and $t^{\prime}$. Hence $\left(v_{2}, t_{1}\right) \subset\left(t_{2}, t_{1}\right)$ and 3.12 imply that $L_{1}$ meets $\Gamma$ at only the points $t_{1}, s_{2}$, $v_{2}$ and $t^{\prime}$. Since $t_{1}$ is a beak, $L_{1} \cap \Gamma\left[t^{\prime}, s_{2}\right]=\left\{\Gamma\left(t^{\prime}\right), \Gamma\left(t_{1}\right), \Gamma\left(s_{2}\right)\right\}$ readily yields that either $\Gamma\left[t_{1}, s_{2}\right] \subset H\left(\Gamma\left[t^{\prime}, t_{2}\right]\right) \subset \Re_{2}$ or $\Gamma\left[t^{\prime}, t_{1}\right] \subset H\left(\Gamma\left[t_{1}, s_{2}\right]\right)$ $=\Re_{1}$. The former yields that $\Re_{1} \subset \Re_{2}$ and $\operatorname{ind}(\Gamma)=0$ and therefore $\Gamma\left[t^{\prime}, t_{1}\right] \subset \Re_{1}$ and in particular $\Gamma\left[t^{\prime}, v_{2}\right] \subset \Re_{1}$. Since $L_{1}$ cuts $\Gamma$ at $t^{\prime}$, $t^{\prime}=v_{1}$ and $L_{1} \neq \Gamma_{1}\left(v_{1}\right)$. Let $\Re_{11}$ and $\Re_{12}$ be the closed regions of $\Re_{1}$ determined by $\Gamma_{1}\left(v_{1}\right)$; that is, $\Re_{11} \cup \Re_{12}=\Re_{1}$ and $\Re_{11} \cap \Re_{12}=\Gamma_{1}\left(v_{1}\right)$ $\cap \Re_{1}$. Let $\Gamma\left(t_{1}\right) \in \Re_{11}$. Then $\Gamma\left[v_{1}, v_{2}\right]$ simple implies that $\left\{\Gamma\left(s_{2}\right), \Gamma\left(v_{2}\right)\right\}$ $\subset \Re_{12}$. Since $\Gamma\left(t_{2}, t_{1}\right)$ is regular and simple, 3.13 and $L_{1} \cap \Gamma\left(v_{2}, v_{1}\right)=$ $\varnothing=L_{1} \cap \Gamma\left(v_{1}, t_{1}\right)$ imply that both $\Gamma\left(v_{2}, v_{1}\right)$ and $\Gamma\left(v_{1}, t_{1}\right)$ are of order two. Hence $\Gamma_{1}\left(v_{1}\right) \neq L_{1}$ yields that $\Gamma_{1}\left(v_{1}\right)$ does not cut $\Gamma$ at any point of $\left[v_{2}, t_{1}\right]$. But $\Gamma\left(t_{1}\right) \in \mathcal{R}_{11}, \Gamma\left(v_{2}\right) \in \mathcal{R}_{12}$ and $\Gamma\left(t_{1}, v_{2}\right) \subset \mathcal{R}_{1}$ simple imply that $\Gamma_{1}\left(v_{1}\right)$ cuts $\Gamma\left(t_{1}, v_{2}\right)$, and hence $\Gamma$, at an odd number of points, a contradiction.

Suppose that $L_{1}$ supports $\Gamma$ at $s_{2}=t_{2}$. We may again assume that $t_{2}$ is a beak. We observe that $L_{1} \cap \Gamma\left(t_{1}, t_{2}\right)=\varnothing$ and by 3.12, $L_{1}$ does not support $\Gamma$ at any point of $\left(t_{2}, t_{1}\right)$. By 3.16 and 3.17 Corollary, $L_{1}$ cuts $\Gamma$ at exactly two points, say $t^{\prime \prime}<t^{\prime}$, in $\left(t_{2}, t_{1}\right)$. Since $t_{1}$ and $t_{2}$ are beaks, we argue as in the preceding and obtain that $t^{\prime}=v_{1}, t^{\prime \prime}=v_{2}, \Gamma\left(v_{2}, v_{1}\right)$ and $\Gamma\left(v_{1}, t_{1}\right)$ are of order two, $\Gamma_{1}\left(v_{1}\right)$ does not cut $\Gamma$ at any point of $\left[v_{2}, v_{1}\right]$ and $\Gamma_{1}\left(v_{1}\right)$ separates $\Gamma\left(t_{1}\right)$ and $\Gamma\left(v_{2}\right)$ in $\Re_{1}$. Hence $\Gamma_{1}\left(v_{1}\right)$ cuts $\Gamma$ at an odd number of points, a contradiction.

Suppose $L_{1}$ cuts $\Gamma$ at $s_{2}$. Then $s_{2}=t_{2}=v_{2}$ and $L_{1}$ cuts $\Gamma$ at exactly one other point $t^{\prime} \in\left(v_{2}, t_{1}\right)$. As in the preceding, $v_{1}=t^{\prime}$ and $\Gamma_{1}\left(v_{1}\right)$ cuts $\Gamma$ at an odd number of points, a contradiction. Thus $t_{1}$ must be a cusp.

Case 2. $s_{1}=t_{1}$ and $L_{1}$ cuts $\Gamma$ at $s_{1}$.

Then $t_{1}=v_{1}$ and $L_{1}$ cuts $\Gamma$ at exactly one other point $t^{\prime \prime} \in\left[s_{2}, t_{1}\right)$. We show that $L_{1}=\Gamma_{1}\left(t_{1}\right)$.

If $t^{\prime \prime}=s_{2}$ then $s_{2}=t_{2}=v_{2}, \Gamma\left(t_{1}, t_{2}\right)$ is of order two and $\Gamma_{1}\left(t_{1}\right) \cap$ $\Gamma\left(t_{1}, t_{2}\right)=\varnothing$. By 3.12, $L_{1}$ does not support $\Gamma$ at any point of $\left(t_{2}, t_{1}\right)$ and hence $L_{1} \cap \Gamma\left(t_{2}, t_{1}\right)=\varnothing$. Then $\Gamma\left(t_{2}, t_{1}\right)$ is of order two by 3.13 and thus $\Gamma_{1}\left(t_{1}\right) \cap \Gamma\left(t_{2}, t_{1}\right)=\varnothing$. If $\Gamma\left(t_{2}\right) \notin \Gamma_{1}\left(t_{1}\right)$, then $\Gamma_{1}\left(t_{1}\right)$ meets $\Gamma$ at exactly the point $\Gamma\left(t_{1}\right)$, a contradiction. Hence $\Gamma_{1}\left(t_{1}\right)=\left\langle\Gamma\left(t_{1}\right), \Gamma\left(t_{2}\right)\right\rangle=L_{1}$.

If $t^{\prime \prime} \neq s_{2}$, then $L_{1}$ supports $\Gamma$ at $s_{2}$ and either $s_{2}=t_{2}$ or $s_{2} \neq t_{2}$ and $t^{\prime \prime}=v_{2}$. As in (1), $s_{2}=t_{2}$ and $L_{1}$ supports $\Gamma$ at $s_{2}$ leads to a contradiction and thus $s_{2} \neq t_{2}$ and $t^{\prime \prime}=v_{2}$. Then $L_{1}$ does not support $\Gamma$ at any point of $\left(v_{2}, v_{1}\right)$ by 3.12 and hence $L_{1} \cap \Gamma\left(v_{2}, t_{1}\right)=\varnothing$ and $\Gamma\left(v_{2}, t_{1}\right)$ is of order 
two. If $\Gamma\left(s_{2}\right) \notin \Gamma_{1}\left(t_{1}\right)$, then $\left|\Gamma_{1}\left(t_{1}\right) \cap \Re_{1}\right|=1$ and in particular $\mid \Gamma_{1}\left(t_{1}\right) \cap$ $\left(\Re_{1} \cup \Gamma\left(v_{2}, t_{1}\right)\right) \mid=1$. This is impossible since $\Gamma=\Gamma\left[t_{1}, v_{2}\right] \cup \Gamma\left(v_{2}, t_{1}\right)$ $\subset \Re_{1} \cup \Gamma\left(v_{2}, t_{1}\right)$ and therefore $L_{1}=\left\langle\Gamma\left(t_{1}\right), \Gamma\left(s_{2}\right)\right\rangle=\Gamma_{1}\left(t_{1}\right)$.

Since $\Gamma_{1}\left(t_{1}\right)$ cuts $\Gamma$ at $t_{1}, t_{1}$ is a cusp or an inflection point. Since $\Gamma_{1}\left(t_{1}\right)$ cuts $\Gamma$ at $t^{\prime \prime}=v_{2}$, there exist $U\left(t_{1}\right)$ and $U\left(v_{2}\right)$ such that $U\left(t_{1}\right) \rightarrow U\left(v_{2}\right)$ by 3.3. Since $\Gamma\left[t_{1}, v_{2}\right] \subset \Re_{1}, \Gamma\left(U^{+}\left(t_{1}\right)\right) \subset \mathrm{bd}\left(\Re_{1}\right)$ and $\Gamma\left(U^{-}\left(v_{2}\right)\right) \subset \Re_{1}$. Then no tangent of $U^{+}\left(t_{1}\right)$ meets $\Gamma\left(U^{-}\left(v_{2}\right)\right)$ and thus $U^{+}\left(t_{1}\right) \leftrightarrow U^{+}\left(v_{2}\right)$ by 3.4. Since $\Gamma\left(v_{2}, t_{1}\right)$ is of order two, $\Gamma\left(U^{-}\left(t_{1}\right)\right) \cup \Gamma\left(U^{+}\left(v_{2}\right)\right) \subset \Gamma\left(v_{2}, t_{1}\right)$ implies that no tangent of $U^{-}\left(t_{1}\right)$ meets $\Gamma\left(U^{+}\left(v_{2}\right)\right)$ and hence $U^{-}\left(t_{1}\right) \leftrightarrow$ $U^{-}\left(v_{2}\right)$. Therefore $U\left(t_{1}\right) \leftrightarrow U\left(v_{2}\right)$ and by 3.4 Corollary, $t_{1}$ is a cusp.

Case 3. $s_{1} \neq t_{1}$.

We note that (1) and (2) are symmetric in $t_{1}$ and $t_{2}$, hence we may assume that $s_{2} \neq t_{2}$. Then $L_{1}=\Gamma_{1}\left(s_{i}\right), s_{i} \neq v_{i}, \Gamma\left(t_{i}\right) \in \operatorname{int}\left(\Re_{1}\right), L_{1}$ supports [cuts] $\Gamma$ at $s_{i}\left[v_{i}\right]$ and $L_{1} \neq \Gamma_{1}\left(v_{i}\right), i=1,2$. Since $L_{1}$ cuts $\Gamma$ at only $v_{1}$ and $v_{2}$, it readily follows from 3.10 and 3.12 that $L_{1}$ meets $\Gamma$ at exactly $s_{1}$, $s_{2}, v_{1}$ and $v_{2}$. By $3.13, \Gamma\left(v_{2}, v_{1}\right)$ is of order two and thus $\left\{\Gamma\left(v_{1}\right), \Gamma\left(v_{2}\right)\right\} \subset$ $\Re_{1}$ implies that either both or neither of $\Gamma\left(s_{1}\right)$ and $\Gamma\left(s_{2}\right)$ are contained in $\Re_{2}^{\prime}=H\left(\Gamma\left[v_{2}, v_{1}\right]\right)$.

As $\left[\Gamma\left(v_{1}\right), \Gamma\left(v_{2}\right)\right\} \subset \Re_{2}, \Re_{2}$ convex implies that $\Gamma\left(v_{1}\right)$ or $\Gamma\left(v_{2}\right)$, say $\Gamma\left(v_{2}\right)$, lies in the boundary of $\Re_{2}$. Let $\Re_{11}$ and $\Re_{12}$ be the closed regions of $\Re_{1}$ determined by $\Gamma_{1}\left(v_{2}\right) ; \Gamma\left(s_{1}\right) \in \Re_{11}$. Let $L_{1}$ be oriented so that $s_{2}<s_{1}$ in $L_{1} \cap \Re_{1}$. Then $\Gamma\left[v_{1}, v_{2}\right] \subset \Re_{1}$ simple implies that $s_{2}<v_{2}<v_{1}$ $<s_{1}$ in $L_{1} \cap \Re_{1}$ and in particular, $\Gamma\left(s_{2}\right) \in \Re_{12}$ and $\Gamma\left(v_{1}\right) \in \Re_{11}$. Since $\Gamma\left(v_{2}\right) \in \operatorname{bd}\left(\Re_{2}\right), \Gamma_{1}\left(v_{2}\right)=\lim L_{\lambda}$ where $L_{\lambda} \cap \Re_{2}=\varnothing$ for each $L_{\lambda}$. In the proof of 3.17, we showed that $L_{\lambda} \cap \Gamma\left[t_{2}, t_{1}\right]=\varnothing$ and $\Gamma\left[t_{1}, t_{2}\right] \subset \Re_{1}$ imply that $L_{\lambda}$ does not separate $\Gamma\left(t_{1}\right)$ and $\Gamma\left(t_{2}\right)$ in $\Re_{1}$. Similarly $L_{\lambda} \cap$ $\Gamma\left[v_{2}, v_{1}\right]=\varnothing$ and $\Gamma\left[v_{1}, v_{2}\right] \subset \Re_{1}$ imply that $L_{\lambda}$ does not separate $\Gamma\left(v_{1}\right)$ and $\Gamma\left(v_{2}\right)$, and hence separates $\Gamma\left(v_{2}\right)$ and $\Gamma\left(s_{2}\right)$, in $\Re_{1}$. Then $\Gamma\left(v_{1}\right) \subset \Re_{11}$ implies that $l_{1} \cap \Re_{2}^{\prime} \subset \Re_{11}$ and $\left\{\Gamma\left(s_{1}\right), \Gamma\left(s_{2}\right)\right\} \cap \Re_{1}^{\prime}=\varnothing$. It is immediate that $\Gamma\left(t_{2}\right) \in \Re_{12}$.

Let $r \in\left(s_{2}, v_{2}\right)$. Since $\Gamma\left(s_{2}, v_{2}\right) \subset \operatorname{int}\left(\Re_{1}\right), 1 \leq\left|\Gamma_{1}(r) \cap \Gamma\left(s_{1}, s_{2}\right)\right| \leq 2$ and $\Gamma_{1}(r)$ cuts $\Gamma\left(s_{1}, s_{2}\right)$ at each point of contact. Let $\Gamma_{1}(r)$ cut $\Gamma$ at $r^{\prime}$ and $r^{\prime \prime}$ in $\left(s_{1}, s_{2}\right)$. Since $\left(s_{2}, t_{2}\right)$ [resp. $\left(t_{2}, s_{2}\right)$ ] is regular, it readily follows from 3.4 Corollary that either $r^{\prime}$ and $r^{\prime \prime}$ are $r$-positive for all $r \in$ $\left(s_{2}, t_{2}\right)\left[\left(t_{2}, s_{2}\right)\right]$ or $r^{\prime}$ and $r^{\prime \prime}$ are $r$-negative for all $r \in\left(s_{2}, t_{2}\right)\left[\left(t_{2}, s_{2}\right)\right]$. Since $\Gamma_{1}\left(s_{2}\right)$ supports $\Gamma$ at $s_{1}$, it is immediate that $s_{1}$ is both $s_{2}$-positive and $s_{2}$-negative and hence $r^{\prime}$ and $r^{\prime \prime}$ are $r$-positive for all $r \in\left(s_{2}, t_{2}\right)$ by 3.5 .

We note that $\left\langle\Gamma\left(v_{1}\right), \Gamma(r)\right\rangle$ tends to $L_{1}$ and $\Gamma_{1}(r)$ tends to $\Gamma_{1}\left(v_{2}\right)$ as $r \in\left(t_{2}, v_{2}\right)$ tends to $v_{2}$. Let $r \in\left(t_{2}, v_{2}\right)$ be arbitrarily close to $v_{2}$. Since $L_{1}$ cuts $\Gamma$ at $v_{1}$ and $v_{2}$ and $\Gamma_{1}\left(v_{2}\right)$ cuts $\Gamma$ at exactly one point of $\left(s_{1}, s_{2}\right)$, we 
may assume by 3.3 that $\left\langle\Gamma\left(v_{1}\right), \Gamma(r)\right\rangle \cap \Gamma\left(v_{1}, r\right)=\varnothing$ and $\mid \Gamma_{1}(r) \cap$ $\Gamma\left(s_{1}, s_{2}\right) \mid=1$. Then $r^{\prime}=r^{\prime \prime}$ and by 3.13, $\Gamma\left(r, v_{2}\right)$ is of order two with $\Re_{2}^{\prime} \subset H\left(\Gamma\left[r, v_{1}\right]\right)$. Let $\Gamma_{1}\left(v_{2}\right)$ cut $\Gamma$ at the point $r_{2}^{\prime} \in\left(s_{1}, s_{2}\right)$ and $\Gamma_{1}(r)$ meet $L_{1}$ at the point $p$. Since $L_{1} \cap \Re_{2}^{\prime} \subset \Re_{11}$ and $\Gamma\left(s_{2}\right) \notin \Re_{11}, 1.3$ and $\Re_{2}^{\prime} \subset H\left(\Gamma\left[r, v_{1}\right]\right)$ clearly imply that $p \notin \mathcal{R}_{11}$; that is, $s_{2}<p<v_{2}$ in $L_{1} \cap \Re_{1}$. Since $\Gamma\left[s_{1}, s_{2}\right] \cup\left(L_{1} \cap \Re_{1}\right)$ is convex, $s_{2}<p<v_{2}$ in $L_{1} \cap \Re_{1}$ readily yields that $s_{1}<r^{\prime}<r_{2}^{\prime}$ in $\left(s_{1}, s_{2}\right)$. Since $r^{\prime}$ tends to $r_{2}^{\prime}$ in $\left(s_{1}, s_{2}\right)$ as $r$ tends to $v_{2}$ in $\left(t_{2}, v_{2}\right)$, it follows that $r^{\prime}$ and $r^{\prime \prime}$ are $r$-positive for all $r \in\left(t_{2}, v_{2}\right)$.

Let $\Gamma_{1}\left(t_{2}\right)$ cut $\Gamma$ at $s \in\left(s_{1}, s_{2}\right)$. By 3.3 , there exist $U\left(t_{2}\right) \subset\left(s_{2}, v_{2}\right)$ and $U(s) \subset\left(s_{1}, s_{2}\right)$ such that $U\left(t_{2}\right) \rightarrow U\left(s_{2}\right)$. As $U^{-}\left(t_{2}\right) \subset\left(s_{2}, t_{2}\right), U^{+}$ $\left(t_{2}\right) \subset\left(t_{2}, v_{2}\right), 1.3$ and the preceding imply that $U^{-}\left(t_{2}\right) \leftrightarrow U^{-}\left(s_{2}\right)$ and $U^{+}\left(t_{2}\right) \leftrightarrow U^{+}\left(s_{2}\right)$. Hence $t_{2}$ is a cusp by 3.4 Corollary.

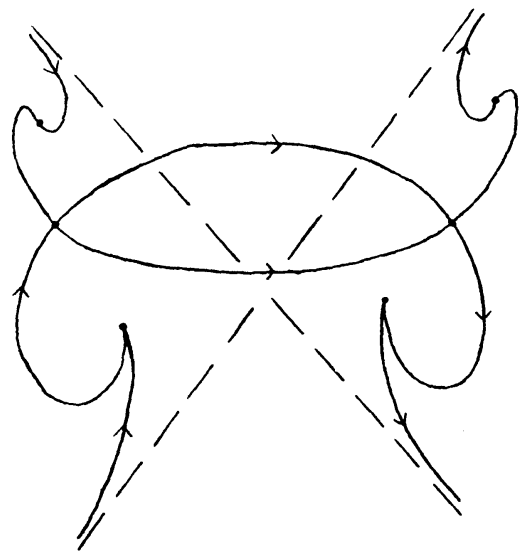

FIGURE 5

Thus $n_{2}=0$ implies that $n(\Gamma) \geq 4$. In Figure 5, we represent a curve with $n_{1}=n_{3}=2$ and $n_{2}=0$.

\section{REFERENCES}

[1] O. Haupt and H. Künneth, Geometrische Ordnungen, Springer-Verlag, Berlin, 1967.

[2] F. A. Möbius, Über die Grundformen der Linien dritter Ordnung, Ges. Werke II, Leipzig, 1886.

[3] R. Park, Topics in direct differential geometry, Canad. J. Math., 24 (1972) 98-148.

Received May 28, 1981 and in revised form February 10, 1982.

UNIVERSITY OF CALGARY

Calgary, Alberta, Canada T2N 1N4 



\title{
PACIFIC JOURNAL OF MATHEMATICS EDITORS
}

\author{
Donald BabBitT (Managing Editor) \\ University of California \\ Los Angeles, CA 90024 \\ Hugo RossI \\ University of Utah \\ Salt Lake City, UT 84112 \\ C. C. Moore and Arthur Ogus \\ University of California \\ Berkeley, CA 94720
}

J. DugundiI

Department of Mathematics

University of Southern California

Los Angeles, CA 90089-1113

R. FinN and H. SAMELSON

Stanford University

Stanford, CA 94305

\section{ASSOCIATE EDITORS}
R. ARENS
E. F. BECKENBACH
B. H. NeUmanN
F. WOLF
K. YosHida
(1906-1982)

\section{SUPPORTING INSTITUTIONS}

\author{
UNIVERSITY OF ARIZONA \\ UNIVERSITY OF BRITISH COLUMBIA \\ CALIFORNIA INSTITUTE OF TECHNOLOGY \\ UNIVERSITY OF CALIFORNIA \\ MONTANA STATE UNIVERSITY \\ UNIVERSITY OF NEVADA, RENO \\ NEW MEXICO STATE UNIVERSITY \\ OREGON STATE UNIVERSITY
}

\author{
UNIVERSITY OF OREGON \\ UNIVERSITY OF SOUTHERN CALIFORNIA \\ STANFORD UNIVERSITY \\ UNIVERSITY OF HAWAII \\ UNIVERSITY OF TOKYO \\ UNIVERSITY OF UTAH \\ WASHINGTON STATE UNIVERSITY \\ UNIVERSITY OF WASHINGTON
}

The Supporting Institutions listed above contribute to the cost of publication of this Journal, but they are not owners or publishers and have no responsibility for its content or policies.

Mathematical papers intended for publication in the Pacific Journal of Mathematics should be in typed form or offset-reproduced (not dittoed), double spaced with large margins. Please do not use built up fractions in the text of the manuscript. However, you may use them in the displayed equations. Underline Greek letters in red, German in green, and script in blue. The first paragraph must be capable of being used separately as a synopsis of the entire paper. In particular it should contain no bibliographic references. Please propose a heading for the odd numbered pages of less than 35 characters. Manuscripts, in triplicate, may be sent to any one of the editors. Please classify according to the scheme of Math. Reviews, Index to Vol. 39. Supply name and address of author to whom proofs should be sent. All other communications should be addressed to the managing editor, or Elaine Barth, University of California, Los Angeles, California 90024.

There are page-charges associated with articles appearing in the Pacific Journal of Mathematics. These charges are expected to be paid by the author's University, Government Agency or Company. If the author or authors do not have access to such Institutional support these charges are waived. Single authors will receive 50 free reprints; joint authors will receive a total of 100 free reprints. Additional copies may be obtained at cost in multiples of 50 .

The Pacific Journal of Mathematics is issued monthly as of January 1966. Regular subscription rate: $\$ 132.00$ a year (6 Vol., 12 issues). Special rate: $\$ 66.00$ a year to individual members of supporting institutions.

Subscriptions, orders for numbers issued in the last three calendar years, and changes of address should be sent to Pacific Journal of Mathematics, P.O. Box 969, Carmel Valley, CA 93924, U.S.A. Old back numbers obtainable from Kraus Periodicals Co., Route 100, Millwood, NY 10546.

The Pacific Journal of Mathematics ISSN $0030-8730$ is published monthly by the Pacific Journal of Mathematics at P.O. Box 969, Carmel Valley, CA 93924. Application to mail at Second-class postage rates is pending at Carmel Valley, California, and additional mailing offices. Postmaster: Send address changes to Pacific Journal of Mathematics, P. O. Box 969, Carmel Valley, CA 93924.

PUBLISHED BY PACIFIC JOURNAL OF MATHEMATICS, A NON-PROFIT CORPORATION

Copyright $\odot 1983$ by Pacific Journal of Mathematics 


\section{Pacific Journal of Mathematics}

Vol. 109, No. $2 \quad$ June, 1983

Tibor Bisztriczky, On the singularities of almost-simple plane curves . . . . 257

Peter B. Borwein, On Sylvester's problem and Haar spaces .............. 275

Emilio Bujalance, Cyclic groups of automorphisms of compact nonorientable Klein surfaces without boundary ............... 279

Robert Jay Daverman and John J. Walsh, Acyclic decompositions of

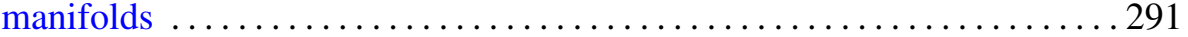

Lester Eli Dubins, Bernstein-like polynomial approximation in higher

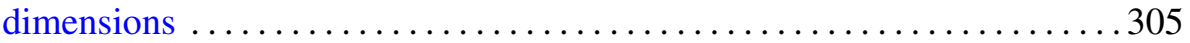

Allan L. Edelson and Jerry Dee Schuur, Nonoscillatory solutions of

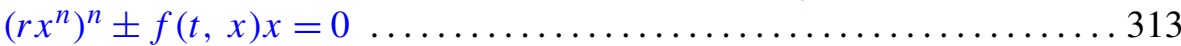

Akira Endô, On units of pure quartic number fields ................. 327

Hector O. Fattorini, A note on fractional derivatives of semigroups and

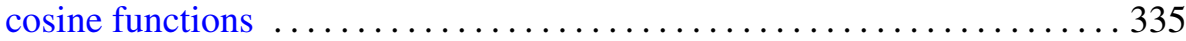

Ronald Fintushel and Peter Sie Pao, Circle actions on homotopy spheres with codimension 4 fixed point set ........................ 349

Stephen Michael Gagola, Jr., Characters vanishing on all but two

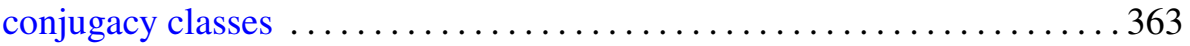

Saverio Giulini, Singular characters and their $L^{p}$ norms on classical Lie

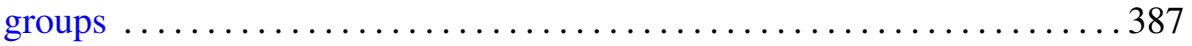

Willy Govaerts, Locally convex spaces of non-Archimedean valued continuous functions

Wu-Chung Hsiang and Bjørn Jahren, A remark on the isotopy classes of diffeomorphisms of lens spaces $\ldots . \ldots \ldots \ldots \ldots \ldots$

Hae Soo Oh, Compact connected Lie groups acting on simply connected 4-manifolds

Frank Okoh and Frank A. Zorzitto, Subsystems of the polynomial system

Knut Øyma, An interpolation theorem for $H_{E}^{\infty}$

Nikolaos S. Papageorgiou, Nonsmooth analysis on partially ordered vector spaces. II. Nonconvex case, Clarke's theory ........ 